\title{
Forelimb myology of loons (Gaviiformes), with comments on the relationship of loons and tubenoses (Procellariiformes)
}

\author{
MARY C. McKITRICK \\ Museum of Zoology and Department of Biology, University of Michigan, Ann Arbor, \\ MI 48109, U.S.A.
}

Received December 1989, accepled for publication September 1990

\begin{abstract}
Descriptions and illustrations of the forelimb musculature of loons (Gavia) and diving petrels (Pelecanoides) were made to determine whether variation in this morphological system reflects a proposed relationship between gaviiforms (loons) and procellariiforms ('tubenoses'). Several previously undescribed muscles were found, as well as several of questionable homology. The data obtained were pooled with information from the literature and analysed cladistically. A sister-group relationship between loons and tubenoses is not supported. Wing muscles of birds have not been extensively studied, and much descriptive and comparative work is needed before this system can contribute significantly toward the understanding of phylogenetic relationships among birds.
\end{abstract}

KEY WORDS:- Loons - tubenoses - wing myology - phylogeny.

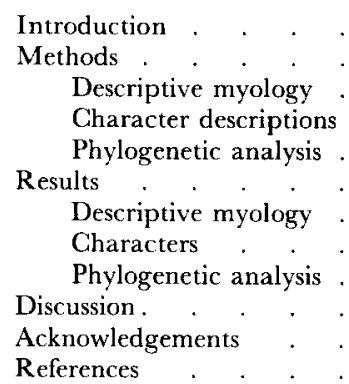

\section{CONTENTS}

\section{INTRODUGTION}

Higher level phylogenetic relationships of birds are currently undergoing much scrutiny and re-evaluation, both by morphologists and molecular biologists. Recent work by C. G. Sibley and colleagues (Sibley, Ahlquist \& Monroe, 1988) based on DNA hybridization, and by Cracraft (1981, 1988) based on character data, has served to underscore the sometimes tenuous foundation of our current classifications and the gaps in our information base on morphology, behaviour and genetics of birds. The present paper attempts to place a preliminary study of the forelimb myology of loons (Gaviiformes) and 
tubenoses (Procellariiformes) into a phylogenetic framework, to determine whether the close phylogenetic relationship of these groups suggested by Cracraft (1981, 1988), Sibley et al. (1988) and earlier workers, is reflected in the patterns of variation in the wing musculature. As such, it also serves to underscore the significant gaps in comparative data on the forelimb musculature of birds.

Loons have been variously regarded as being closely related to grebes (Podicipediformes), auks (Alcidae), penguins (Sphenisciformes), sun-grebes (Heliornithidae), pelecaniformes, tubenoses, gulls (Laridae) or ducks (Anatidae), while the majority of authors have thought tubenoses to be most closely related to penguins and, less frequently suggested, auks, gulls, loons or grebes (see review in Sibley \& Ahlquist, 1972). Cracraft (1981) placed Sphenisciformes, Gaviiformes (including grebes), Procellariiformes and Pelecaniformes in his Division 1 on the basis of anatomical evidence, and regarded loons and grebes to be sister groups (Cracraft, 1982). Data from DNA hybridization suggest that Gaviidae (loons) and Procellariidae (storm-petrels, shearwaters, petrels, diving-petrels and albatrosses) are sister groups, with penguins being their sister group and frigatebirds the sister group to the entire assemblage (Sibley et al., 1988). In this scheme, grebes are fairly distant from the loon-tubenose group. Mayr \& Cottrell (1979) listed these taxa in the following sequence: Procellariiformes, Sphenisciformes, Gaviiformes, Podicipediformes, Pelecaniformes.

The present study offers a review of data from the forelimb musculature of birds and a preliminary evaluation of the evidence this body of data offers towards understanding phylogenetic relationships among birds. In the first part of this study, descriptions of the forelimb musculature of two species of loons and a diving petrel are presented. In the second, the literature on variation in forelimb musculature in birds is reviewed and analysed using numerical cladistic methods. Information on wing musculature is surprisingly limited, with complete data available for only a few dozen taxa in the literature. This review reveals the need for much additional descriptive work before a truly comprehensive phylogenetic analysis of this anatomical system can be presented. It is hoped that the data matrix can eventually be expanded to include many additional taxa, and that it can be combined with data from many additional character systems (e.g. McKitrick, in press) to produce a more thorough analysis of phylogenetic relationships among birds.

\section{METHODS}

\section{Descriptive myology}

Spirit specimens of Gavia immer (two specimens) and G. stellata (one specimen) (Gaviiformes), and Pelecanoides garnoti (two specimens) (Procellariiformes) were dissected and observations made of all extrinsic and intrinsic forelimb muscles. Dissections were performed under a stereomicroscope at $6 \times$ and $12 \times$ magnifications, using a reversible iodine stain (Bock \& Shear, 1972) to increase visibility of muscle fibres. Drawings were made free hand (loons) or with a camera lucida microscope attachment; these were then rendered in ink by an illustrator. Anatomical nomenclature follows Baumel et al. (1979); for synonymy with older names of muscles see Raikow (1985). Museum names from which 
specimens were borrowed are abbreviated as follows: CM: Carnegie Museum of Natural History; UMMZ: University of Michigan Museum of Zoology; USNM: National Museum of Natural History (United States); YPM: Peabody Museum of Natural History (Yale).

Descriptions are for Gavia immer CM 2320, with variations for other specimens and species as noted. Descriptions of Pelecanoides garnoti are based on UMMZ 225241 with exceptions as noted. When asymmetrical, left and right sides are designated ' $L$ ' and ' $R$ '.

\section{Character descriptions}

The characters presented in the annotated list (see Results: Characters) were chosen for discussion because they are variable within birds or differ in loons and/or diving-petrels from the conditions described in other birds (George \& Berger, 1966: 288). Character data from the sources cited below are summarized in Table 1, with taxa listed as they appear in these sources; e.g. 'Procellariiformes', as indicated in George \& Berger (1966) for character 9, is included in the table as well as Pelecanoides from the present study. George \& Berger (1966) noted the occurrence of unusual conditions and summarized available information for many species or groups of birds. Frequently they gave no references, indicating the information came from the authors' unpublished observations or from the extensive work of G. E. Hudson and colleagues. Presumably if a taxon was not specifically mentioned in such a notation whereas it was mentioned in other descriptions, then members of that taxon lack the unusual condition. Such cases are given a dash $(-)$ in Table 1 and are treated as unknown. If an original reference failed to discuss a condition and it is not clear from the description or figures whether the condition is present in that taxon, a '?' is entered in Table 1.

\section{Phylogenetic analysis}

The taxa for which complete data are available include one paleognath (a tinamou) and 15 neognath taxa. Data from DNA hybridization (Sibley et al., 1988) and from molecular and morphological character data (Cracraft, 1988; Cracraft \& Mindell, 1989) suggest that paleognaths (ratites and tinamous) are monophyletic and that they are the sister group to the neognaths, which are also monophyletic. I accept these hypotheses for the purpose of this analysis and designate tinamous as the outgroup and neognaths as the ingroup, but make no assumptions about relationships within the ingroup. I analysed the data using PAUP 3.0e (Swofford, 1989). Several taxa showed polymorphism in characters 12 and 13; these are coded as ' $A$ ' in the matrix; missing data are coded as '?'. Only those taxa for which relatively complete data were available are used in the final analysis; familial or subordinal names are used in the matrix and the cladograms. The matrix is presented as Table 2. The analysis was performed using the Heuristic algorithm, with tree-bisection branch swapping and random addition. 


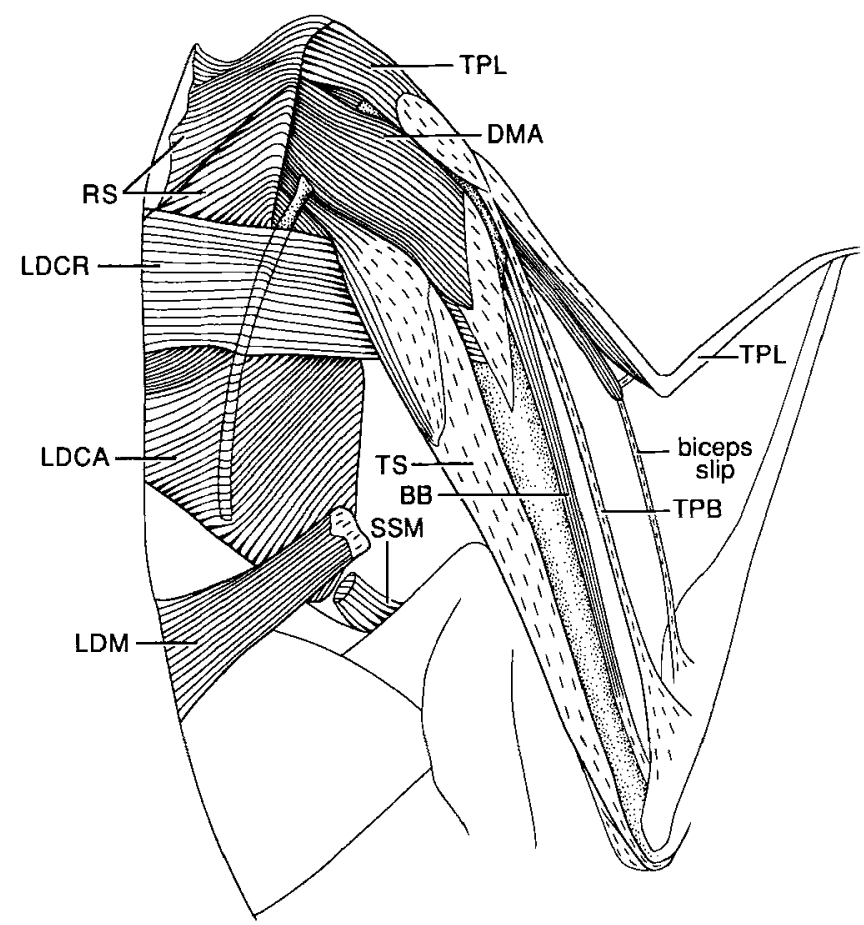

Figure 1. Superficial dorsal muscles of the forelimb, Gavia immer. Abbreviations for Figs 1-21: ABA, M. abductor alulae; ADA, M. adductor alulae; ADM, M. adductor digiti majoris; B, M. brachialis; BB, M. biceps brachii; CCA, M. coracobrachialis caudalis; GUC, M. cucullaris; DMA, M. deltoideus major; DMI, M. deltoideus minor; EC, M. ectepicondylo-ulnaris; EDC, $M$. extensor digitorum communis; ELA, M. extensor longus alulae; ELDM, M. extensor longus digiti majoris; EMR, M. extensor metacarpi radialis; EMU, M. extensor metacarpi ulnaris; ES, M. expansor secundariorum; FCU, M. flexor carpi ulnaris; FDM, M. flexor digiti minoris; FDP, M. flexor digitorum profundus; FDS, M. flexor digitorum superficialis; ha, humeral anchor; ICR, M. iliotibialis cranialis; ID, $\mathbf{M}$. interosseus dorsalis; ITCA, M. iliotrochantericus caudalis IV, $M$. interosseus ventralis; LDCA, M. latissimus dorsi caudalis; LDCR, M. latissimus dorsi cranialis; P, M. pectoralis, pars thoracicus; PPB, M. pectoralis pars propatagialis brevis; PPL, M. pectoralis pars propatagialis longus; PRP, M. pronator profundus; PRS, M. pronator superficialis; RP, $\mathbf{M}$. rhomboideus profundus; RS, M. rhomboideus superficialis; SBC d, M. subcoracoideus caput dorsale; SBC v, M. subcoracoideus caput ventrale; SBS la, M. subscapularis caput laterale; SBS m, M. subscapularis caput mediale; SC, M. sternocoracoideus; SHCA, M. scapulohumeralis caudalis; SHCR, M. scapulohumeralis cranialis; SP, M. serratus profundus; SP ca, M. serratus profundus, caput caudale; SP cr, M. serratus profundus, caput craniale; SP m, M. serratus profundus, caput mediale; SSCA, M. serratus superficialis caudalis; SSCR, M. serratus superficialis cranialis; SSM, M. serratus superficialis medialis; SU, M. supinator; SUP, M. supracoracoideus; tb, tendinous band; TH, M. humerotriceps; TPB, M. tensor propatagialis brevis; TPL, M. tensor propatagialis longus; TS, M. scapulotriceps; UD, M. ulnometacarpalis dorsalis; UV, M. ulnometacarpalis ventralis. A '?' indicates unidentified muscles.

\section{RESULTS}

\section{Descriptive myology}

\section{M. latissimus dorsi (Figs 1-4: LD)}

Pars cranialis (LDCR) is a flat, strap-shaped belly, $32 \mathrm{~mm}$ wide at its origin, arising by a short, wide aponeurosis from the dorsal vertebrae. The thin, flat belly passes laterally and slightly caudad to insert by semitendinous fibres on the dorsolateral surface of the shaft of the humerus, deep to the belly of M. scapulotriceps. It does not narrow at its insertion. 


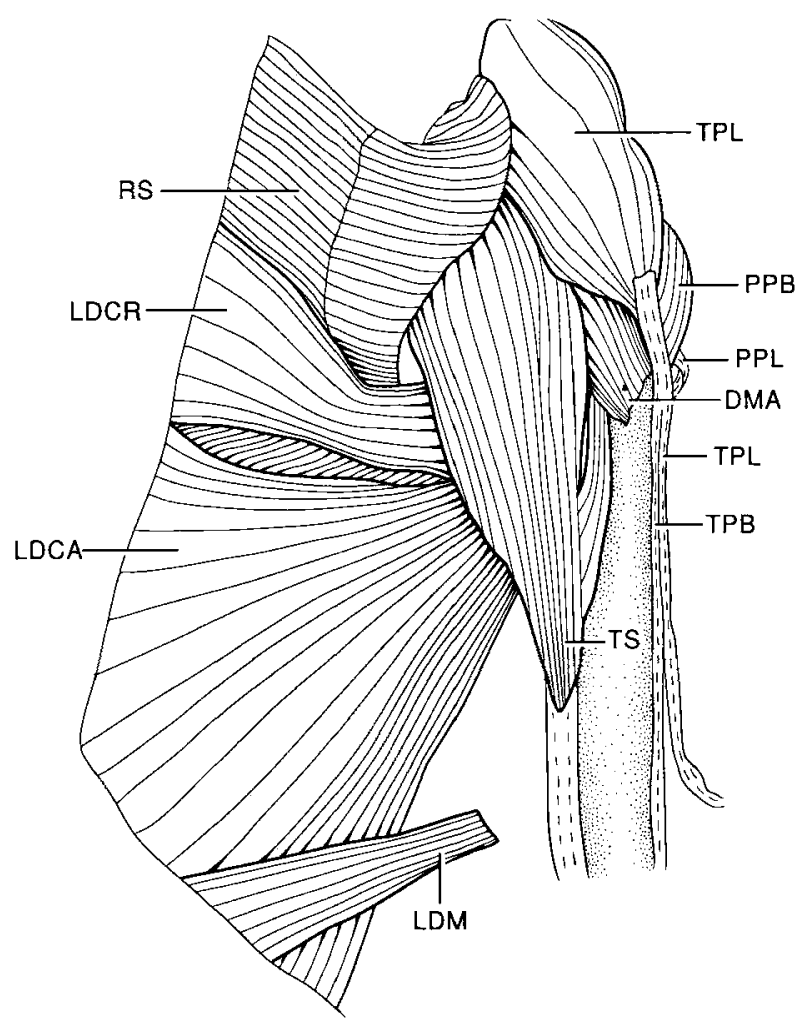

Figure 2. Superficial extrinsic dorsal muscles of the forelimb, Pelecanoides garnoti.

Pars caudalis (LDCA) is a large, triangular belly, separated from cranialis by a gap of $8 \mathrm{~mm}$ in $G$. immer CM 2320. It arises by semitendinous fibres from the dorsal vertebrae cranially, and caudally by an aponeurosis from the medial, cranial and lateral surface of the Ala preacetabularis ilii, deep to the bellies of $\mathrm{Mm}$. iliotrochantericus caudalis, iliotibialis cranialis and iliotibialis lateralis. It narrows considerably as it passes craniad, inserting by a tendon about $3 \mathrm{~mm}$ wide on the Margo caudalis of the humerus, slightly cranial to the insertion of pars cranialis. A narrow, dense tendinous band "'humeral anchor" of George \& Berger, 1966: 293) arising from the deep surface of $\mathbf{M}$. scapulotriceps passes superficial to pars cranialis to fuse with the superficial surface of the tendon of insertion of pars caudalis. The cranial edge of pars cranialis is wedged between the anchor and the insertion of pars caudalis, and is partly fused with them.

Pars metapaiagialis (LDM) is a very thin, flat, strap-shaped belly, $30 \mathrm{~mm}$ wide at its origin and situated $26 \mathrm{~mm}$ caudal to pars caudalis. It arises by semitendinous fibres from the Crista dorsalis of the synsacrum, caudal to the origin of M. iliotibialis lateralis. It narrows as it passes cranioventrad to enter the skin of the dorsum.

G. stellata: As in $G$. immer, but pars cranialis is relatively wider: $32 \mathrm{~mm}$ in the smaller $G$. stellata. Pars metapatagialis is $18 \mathrm{~mm}$ wide at its origin and situated $37 \mathrm{~mm}$ caudal to LDCA. The origin is immediately caudal to the origin of M. IL.

Pelecanoides garnoti: Pars cranialis and metapatagialis are as in $G$. immer, except 


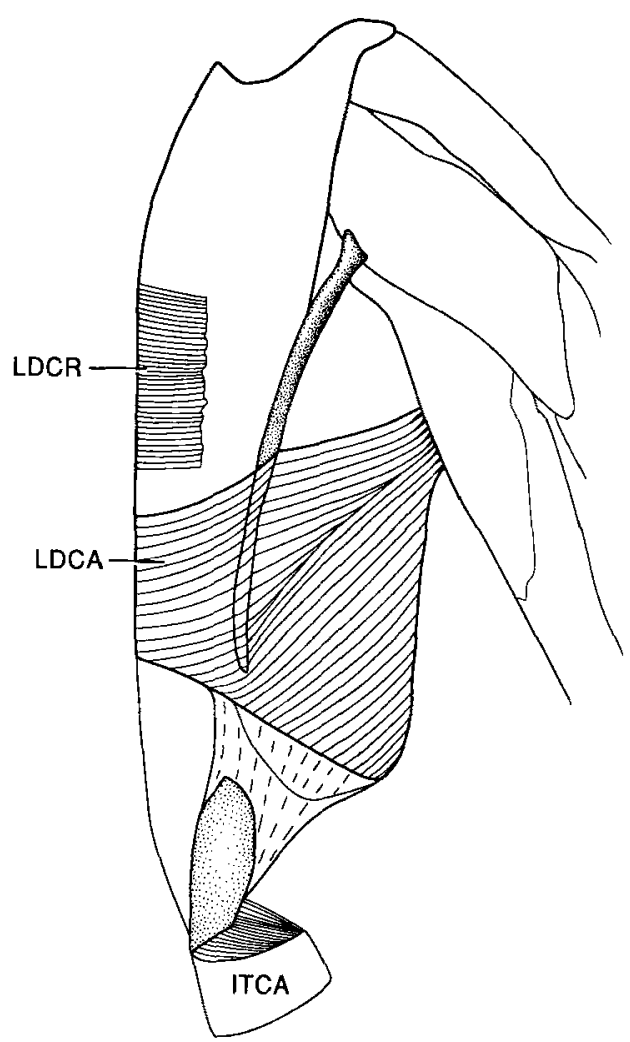

Figure 3. M. latissimus dorsi caudalis, Gavia immer.

cranialis is $10 \mathrm{~mm}$ wide (9 $\mathrm{mm}$ in P. garnoti UMMZ 225240) at its origin and narrows to $4 \mathrm{~mm}$ at the insertion. The dorsal border of pars metapatagialis abuts the ventral border of pars caudalis. Pars caudalis is as in G. immer except that there is also a fleshy origin from the cranial border (flange) of the preacetabular ilium. There is no gap between the origins of caudalis and cranialis, and in UMMZ 225240 there is no line of demarcation between the two origins. In UMMZ 225240 a slip of fibres from pars cranialis fuses onto the dorsal surface of pars caudalis near the distal end of the muscle. The two parts do not fuse at their distal end, but are closely associated, with caudalis lying ventral to cranialis.

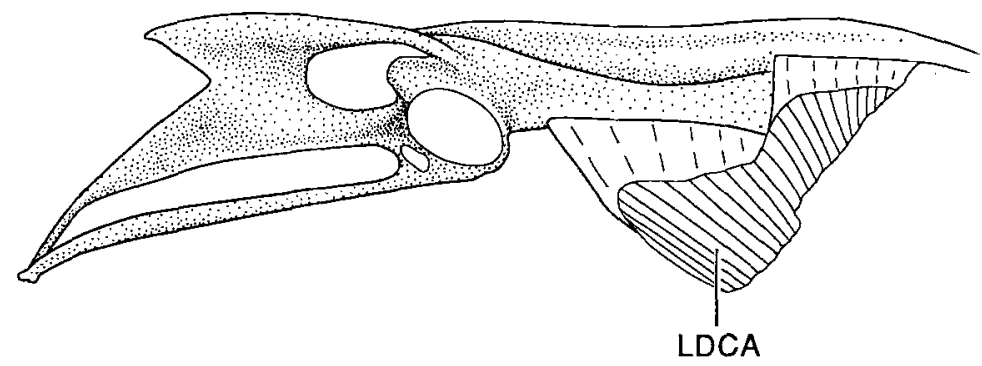

Figure 4. M. latissimus dorsi caudalis, Pelecanoides garnoti. 


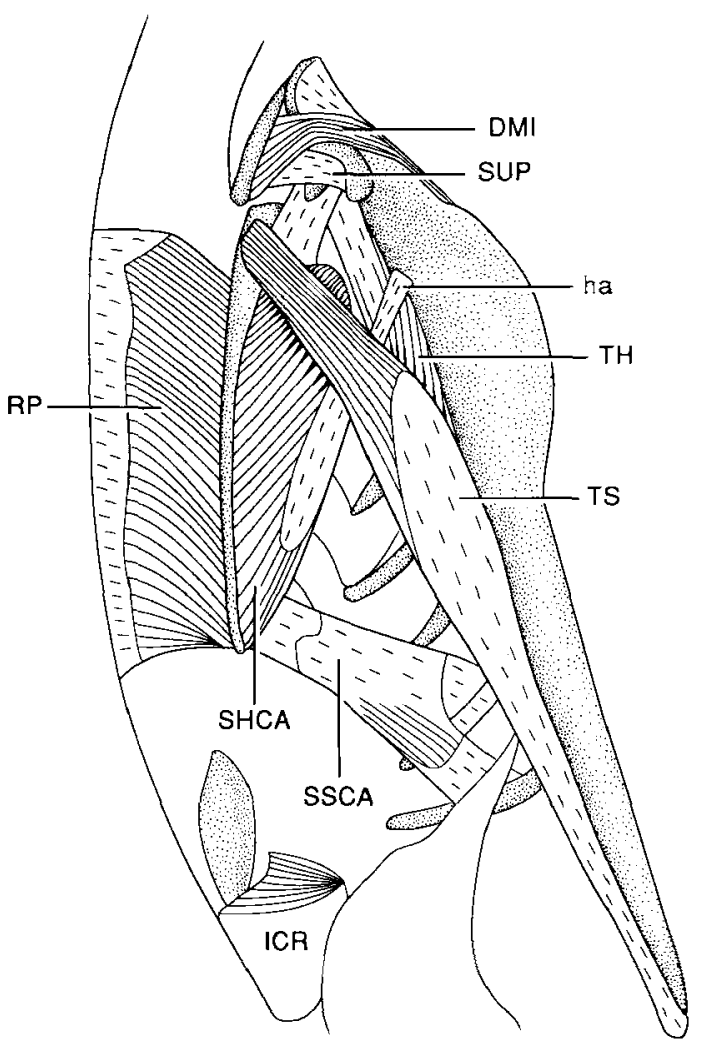

Figure 5. Second layer of extrinsic dorsal muscles of the forelimb, Gavia immer (M. rhomboideus superficialis removed).

Pars cranialis inserts by a very short tendon on the caudodorsal surface of the humeral shaft just distal to the head of the humerus, with caudalis inserting by a longer tendon just ventral to cranialis. The humeral anchor of $M$. scapulotriceps is fused with part of the insertion of pars cranialis and caudalis.

\section{M. rhomboideus superficialis (Figs $1,2,6: \mathrm{RS}$ )}

Arises by an aponeurosis from the last cervical vertebrae and from the dorsal vertebrae cranial to the Ala preacetabularis ilii. The muscle passes craniad to insert by semitendinous fibres on the head of the scapula and on the dorsomedial surface of the proximal three-quarters of the blade of the scapula, caudally. Cranially it inserts on the dorsomedial surface of the dorsal end of the clavicle. In G. immer USNM 504983 the muscle has two heads, a cranial and a caudal one. The cranial head arises from the last cervical vertebrae and inserts semitendinously on the surface of $\mathrm{M}$. deltoideus major caudally, and onto the head of the scapula cranially. The caudal head arises from the dorsal vertebrae and inserts semitendinously on the dorsomedial surface of the proximal threequarters of the scapular blade, and on the dorsal end of the clavicle.

Gavia stellata: As in G. immer CM 2320, but the caudal insertion is on the proximal seven-eighths of the scapula.

Pelecanoides garnoti: As in G. immer CM 2320, except that the scapular insertion 


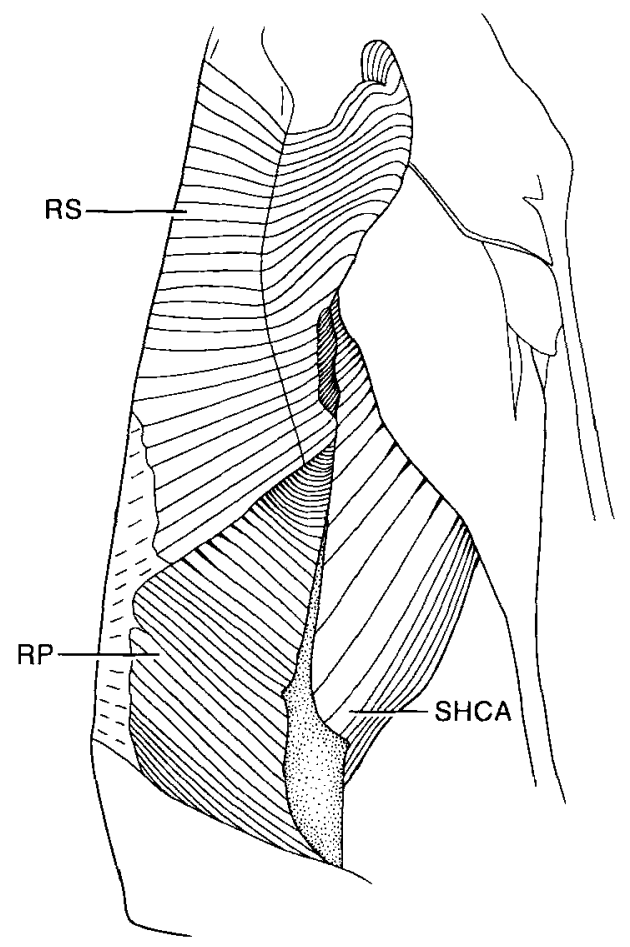

Figure 6. Second layer of extrinsic dorsal muscles of the forelimb, Pelecanoides garnoti.

is on the proximal one-third (one-quarter in UMMZ 225240) of the scapular blade.

\section{M. rhomboideus profundus (Figs 5, 6: RP)}

Lies almost entirely deep to $M$. rhomboideus superficialis, except for a very small triangular portion at the distal end. It arises by a broad aponeurosis from the last cervical and the dorsal vertebrae and inserts semitendinously along the length of the scapular blade.

Gavia stellata: As in G. immer.

Pelecanoides garnoti: As in G. immer except that, due to the shorter length of M. rhomboideus superficialis, more of the muscle is exposed.

\section{M. serratus superficialis (Figs 1, 5, 7, 8: SS)}

Pars cranialis (SSCR) has only one head of origin in loons. It is a parallel-fibred muscle arising fleshy on the lateral surface of the shaft of the first true rib. It passes craniodorsad to insert by a tendon on the ventral margin of the proximal one-quarter of the scapula, between the heads of M. subscapularis.

Pars metapalagialis (SSM) is a small, strap-shaped muscle arising by an aponeurosis from the lateral surface of the first true rib and on the uncinate process of that rib. It passes laterad to insert fleshy into the humeral feather tract.

Pars caudalis (SSCA) is a narrow, fan-shaped muscle arising by an aponeurosis from the lateral surface of the 4th sternal rib and the 1st and 2nd true ribs, and from the intercostal fascia. The flat belly is covered by a thin aponeurosis. It 


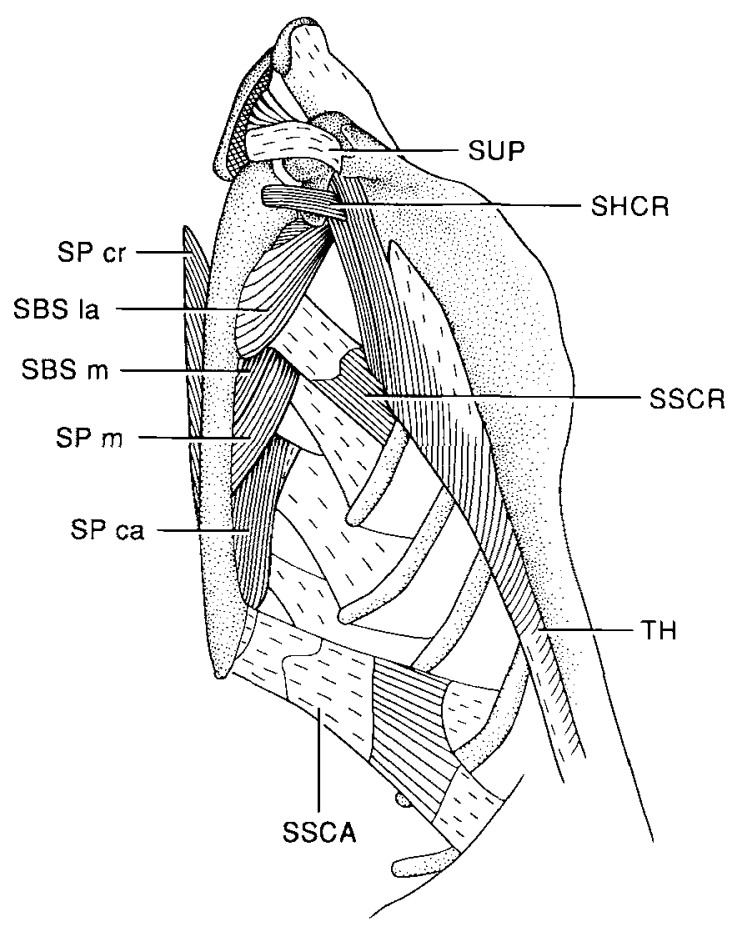

Figure 7. Third layer of extrinsic dorsal muscles of the forelimb, Gavia immer.

passes craniad to insert by an aponeurosis on the ventral surface of the distal one quarter of the scapular blade (distal one-eighth in G. immer USNM 504983). George \& Berger (1966:299) reported that in G. immer the tendon of pars metapatagialis "ends near the elbow by fusing with the tendons of $\mathrm{Mm}$. triceps and expansor secundariorum".

G. stellata: Pars cranialis: as in G. immer CM 2320. Pars metapatagialis arises on the 4th true rib (versus the 1st in $G$. immer), on the lateral surface of the distal end of the dorsal segment. It also arises on the 5th true rib, in the same position. It does not arise on the uncinate process of either of these ribs. Pars caudalis is a narrow, funnel-shaped muscle arising on the uncinate process of the 4th and 5th true ribs, by a Y-shaped, tendinous sheet. The insertion is on the apex of the scapula, by a $2 \mathrm{~mm}$ wide, flat tendon.

Pelecanoides garnoti: Pars cranialis has two heads of origin: one, a thin, flat, parallel-fibred belly from the 1st true rib and the other, deeper (and thicker) belly from the last cervical rib. Both pass between the head of M. subscapularis to insert on the ventral margin of the proximal end of the scapula. Pars metapatagialis is as described in G. immer CM 2320, as is pars caudalis except that the insertion is fleshy, there is no aponeurosis on the muscle's surface, and the origins are fleshy from the 3rd and 4th ribs. Furthermore the cranial edge of the muscle is partially fused with the caudal margin of $M$. serratus profundus medius at the proximal ends.

\section{M. serralus profundus (Figs 7, 8:SP)}

Consists of three heads. The cranial head ( $\mathrm{SP}$ cr) arises from the last cervical vertebrae and inserts fleshy on the dorsomedial surface of the distal half of the 


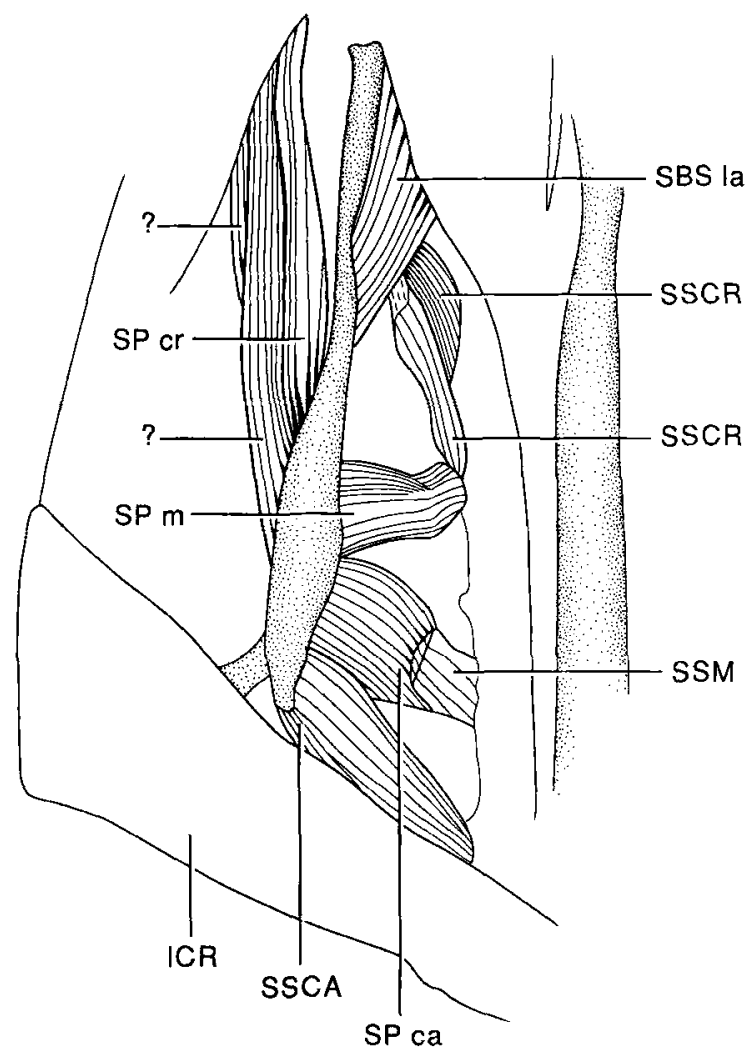

Figure 8. Third layer of extrinsic dorsal muscles of the forelimb, Pelecanoides garnoti.

scapula. The middle ( $\mathrm{SP}$ m) and caudal (SP ca) heads arise by tendinous sheets from the lateral surface of the true ribs, and insert fleshy on the central and distal one-third, respectively, of the ventromedial surface of the scapular blade.

G. stellata: As in G. immer.

Pelecanoides garnoti: As in $G$. immer except that pars cranialis inserts semitendinously; pars medius arises from rib 1 and the insertion is on the ventromedial margin of the middle of the scapula; pars caudalis arises from rib 2 and inserts on the ventromedial margin of the distal end of the scapula.

Two unidentified muscles occur adjacent to $M$. serratus profundus in Pelecanoides (Fig. 8): (1) a flat, triangular sheet of muscle arises from the last cervical vertebrae and from the last cervical rib and the first true rib; it inserts fleshy on the medial surface of the distal half of the scapula (see drawing); (2) a flat sheet of muscle similar to 1 and arising medial (deep) to it, but with a vertebral origin only. It inserts on the medial surface of the scapula just distal to the insertion of 1 . These two small muscles do not, to my knowledge, fit any published descriptions.

\section{M. scapulohumeralis cranialis}

Absent in Gavia immer CM 2320, but present in G. immer USNM 504983. Sanders $(1967: 103)$ found it in $G$. immer as well. It is a tiny, parallel-fibred muscle, arising by a short tendon from the dorsolateral surface of the head of the 
scapula. It inserts on the medial surface of the head of the humerus, on the Crus ventrale fossae between the two heads of origin of $\mathrm{M}$. humerotriceps.

G. stellala: As in G. immer USNM 504983.

Pelecanoides garnoti: As in Gavia although relatively larger; its origin extends to the proximal part of the scapular blade.

M. scapulohumeralis caudalis (Figs 5, 6:SHCA) A fan-shaped muscle arising semitendinously on the dorsolateral surface of the entire length of the scapular blade and by an aponeurosis from the ventrolateral surface of the blade. It passes cranioventrad to insert by a stout tendon in the ventral (large) Fossa pneumotricipitalis of the humerus, where it is surrounded by the fibres of origin of M. humerotriceps.

G. stellata: As in G. immer.

Pelecanoides garnoti: As in Gavia except the origin is from the central three-fifths of the scapular blade dorsally, and ventrally the aponeurosis is from the central five-eighths of the blade. The insertion is on the ventral border of the (single) fossa, not in it. It lies superficial to the insertion of $M$. humerotriceps.

\section{M. subscapularis (Figs 7-10: SBS)}

Consists of a lateral and a medial head. Pars lateralis is fan-shaped and arises by semitendinous fibres from the proximal one-third of the ventrolateral surface of the shaft of the scapula. Pars medialis is fan-shaped and arises fleshy from the ventral surface of the proximal half of the medial surface of the scapular blade, and from the ventral surface of the proximal end of the coracoid. The two bellies insert, with the dorsal head of M. subcoracoideus, by a common tendon on the Tuberculum ventrale of the humerus.

$G$. stellata: As in $G$. immer except there is no coracoidal origin for pars medialis.

Pelecanoides garnoti: The medial head is as in $G$. immer. The lateral head arises on the proximal half of the scapular blade; fibres from this head extend the length of the tendon of insertion. The fibres end on the tendon itself, however, not on bone. The insertion is not with $\mathrm{M}$. subcoracoideus, but by a stout tendon near the Sulcus ligamentus transversus of the humerus.

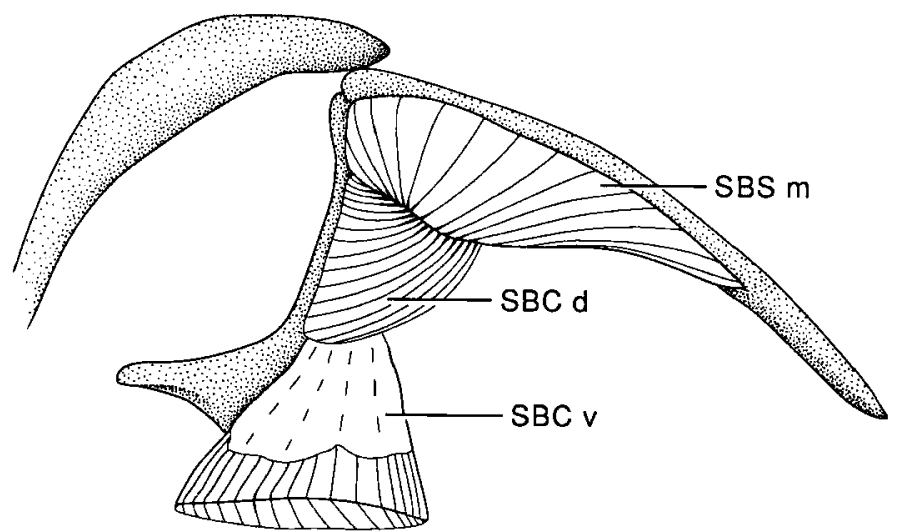

Figure 9. Muscles of the medial surface of the scapula and coracoid, Gavia immer. 


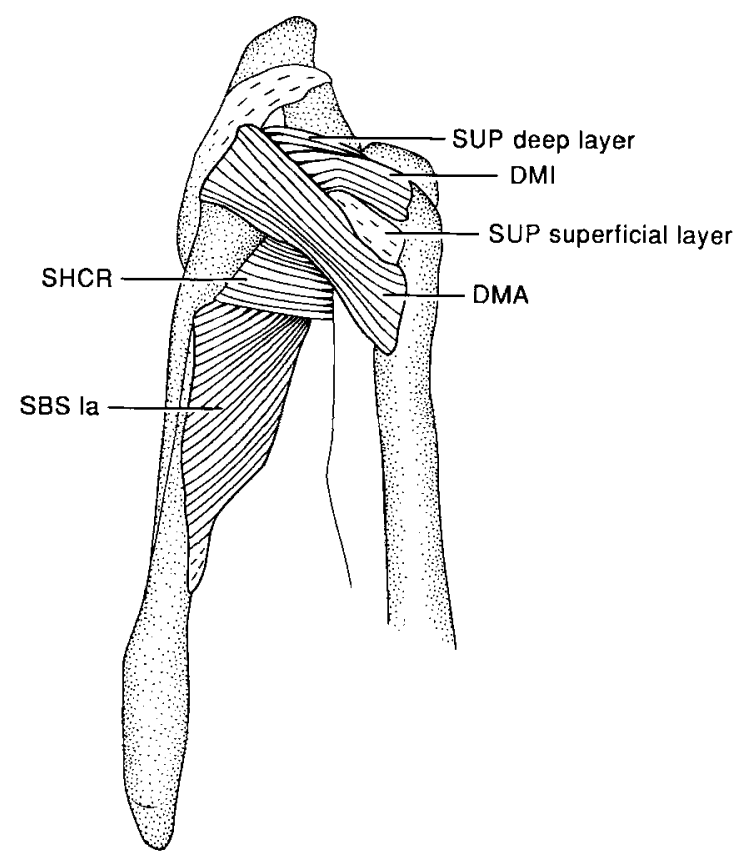

Figure 10. Muscles of the medial surface of the scapula and coracoid, Pelecanoides garnoti.

\section{M. subcoracoides (Fig. 9: $\mathrm{SBC}$ )}

Consists of a dorsal and a ventral head. The small fan-shaped dorsal head arises fleshy from the coracoclavicular membrane and the central portion of the ventrolateral surface of the shaft of the coracoid. The longer, ventral head arises fleshy from the craniolateral edge of the sternum and from the ventral surface of the distal three-quarters of the coracoidal shaft. The two heads fuse distally to insert tendinously in common with $M$. subscapularis on the Tuberculum ventrale of the humerus.

G. stellata: As in G. immer.

Pelecanoides garnoti: As in G. immer, but the dorsal head also arises on the ventral surface of the head of the scapula and the proximal quarter of the ventral surface of the scapular blade. It inserts by a short, stout tendon on the Tuberculum ventrale, but not in common with M. subscapularis.

M. coracobrachialis cranialis (Figs 13, 14: CCR)

A tiny muscle arising fleshy from the dorsal surface of the shaft of the coracoid. It passes craniad to insert by a short tendon on the Tuberculum ventrale of the humerus.

G. stellata: As in G. immer.

Pelecanoides garnoti: As in Gavia but it is relatively wider and the insertion abuts the Sulcus ligamentus transversus, superficial to the insertion of M. subscapularis.

M. coracobrachialis caudalis (Figs 13, 14: CCA)

A narrow, fan-shaped muscle arising by a thin aponeurosis from the craniolateral surface of the sternum lateral to $M$. supracoracoideus, and by 


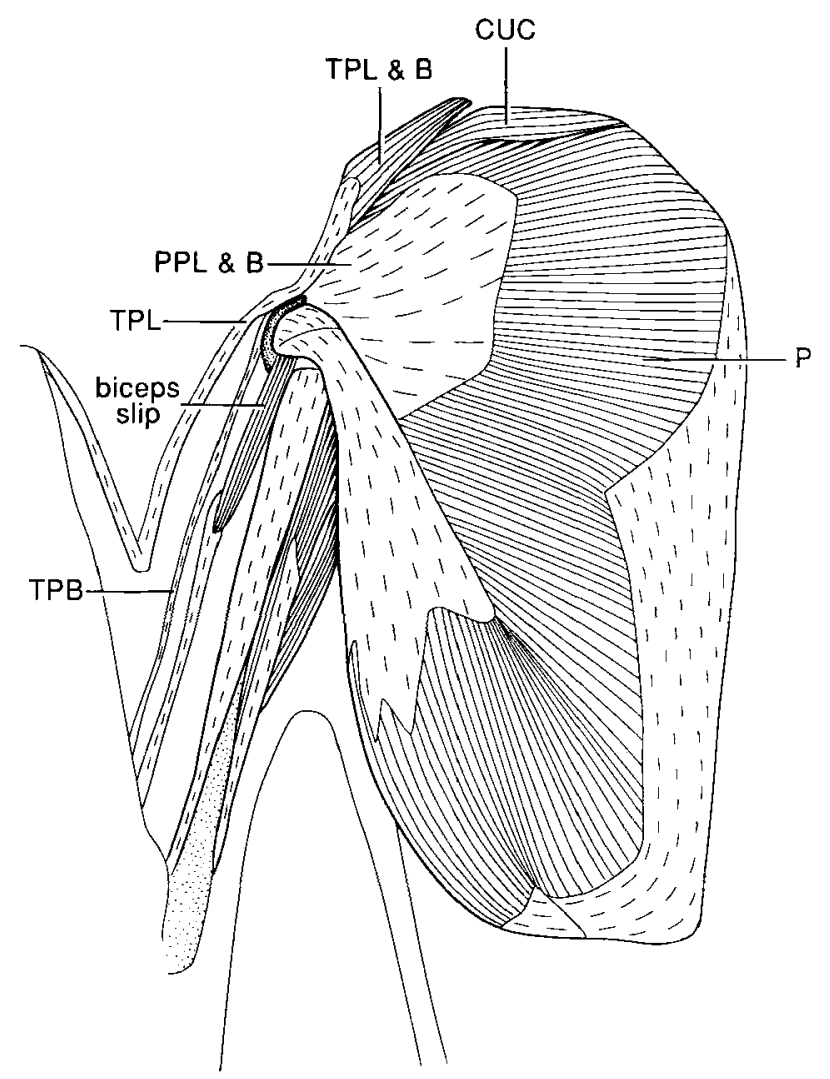

Figure 11. Superficial extrinsic ventral muscles of the forelimb, Gavia immer.

fleshy fibres from the ventrolateral surface of the distal two-thirds of the shaft of the coracoid. It inserts by a stout tendon in the Incisura capitis of the humerus.

G. stellata: As in G. immer.

Pelecanoides garnoti: As in Gavia, except the coracoidal origin is less extensive, just from the distal end of the coracoid.

\section{M. sternocoracoideus (Figs 13, 14:SC)}

A fan-shaped muscle arising fleshy from the sternal end of the sternal ribs and from the sternocoracoidal process of the sternum. It inserts by tendinous fibres on the Impressio sternocoracoidei and the Processus lateralis of the ventral surface of the coracoid.

G. stellata and Pelecanoides garnoti: As in G. immer.

\section{M. pectoralis (Figs 11-15)}

Pars thoracicus $(\mathbf{P})$ is the most superficial muscle on the lateral surface of the pectoral girdle. It is large and fan-shaped, and is divided into a superficial and a smaller, deep layer about two-thirds the extent of the other. The superficial layer arises fleshy from all but the distal $20 \mathrm{~mm}$ of the sternal carina $(40 \mathrm{~mm}$ in G. immer USNM 504983), from the lateral surface of the clavicle and from the craniolateral surface of the coracoclavicular membrane. The most cranial fibres pass ventral to the clavicle to meet the corresponding fibres on the other side of 


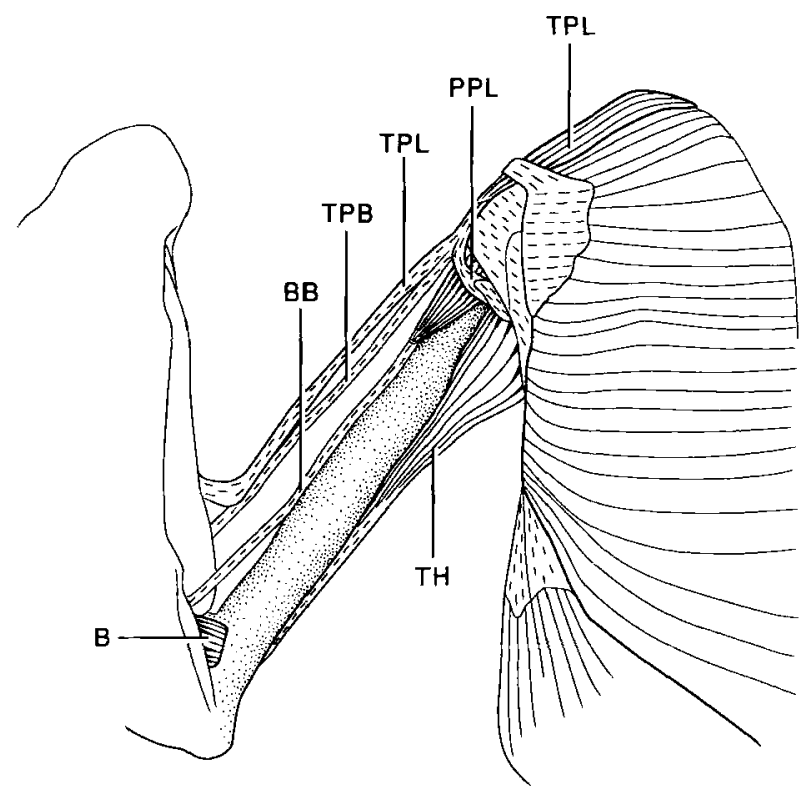

Figure 12. Superficial extrinsic ventral muscles of the forelimb, Pelecanoides garnoti.

the body. Three bundles of fibres converge toward the proximal end of the humerus to insert on the Crista pectoralis by semitendinous fibres and by a dense aponeurosis arising on the craniolateral surface of the muscle. The lateral group of fibres extends beyond the lateral edge of the sternal plate by as much as $30 \mathrm{~mm}$.

The deep layer arises by an aponeurosis from the sternal plate and the sternal ribs and merges with the superficial layer laterally. It inserts by a tendon about $40 \mathrm{~mm}$ long on the lateroventral surface of the head of the coracoid, on the lateral surface of the tip of the clavicle, and on the ligamentous tissue surrounding the head of the humerus.

Pars propatagialis longus (Figs 11, 12: PPL) is a broad triangular belly arising from the aponeurotic sheet covering the craniolateral surface of pars thoracicus. It joins the tendon of $M$. tensor propatagialis longus at an acute angle.

Pars propatagialis brevis (Figs 11, 12: PPB) is a tiny, strap-shaped tendon arising from the aponeurosis on the craniolateral surface of pars thoracicus, caudal to the origin of PPL. It joins the belly of pars propatagialis longus at an acute angle.

G. stellata: As in G. immer, but pars thoracicus arises from the entire length of the sternal carina, and the cranial fibres do not pass ventral to the clavicle. The lateral fibres insert tendinously. Pars propatagialis brevis and longus are a single entity. Apparently they are not distinct from pars thoracicus. They arise as a dense aponeurosis from the superficial surface of pars thoracicus near its insertion on the humerus, inserting by a dense aponeurosis on the ventral edge of the common belly of $\mathrm{M}$. tensor propatagialis longus et brevis.

Pelecanoides garnoti: Pars thoracicus arises from the entire length of the sternal carina. The cranial fibres do not pass ventral to the clavicle. The deeper layer is about half the size (two-fifths in UMMZ 225240) of the superficial layer, and it 


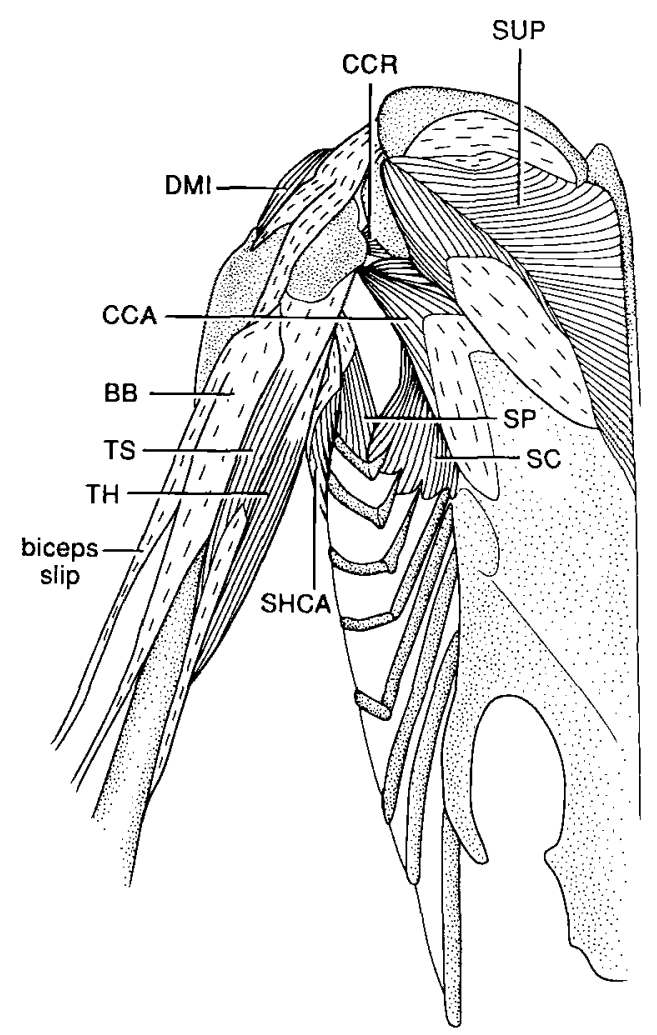

Figure 13. Second layer of extrinsic ventral muscles of the forelimb, Gavia immer.

inserts by tendinous fibres on the head of the humerus. Pars propatagialis brevis is a small, fleshy belly arising from the surface of pars thoracicus very near the latter's insertion on the Crista pectoralis of the humerus. It joins the tendon of M. TPL at an acute angle. What appears to be pars propatagialis longus is different from any other bird described and the homology of this muscle to M. PPL is in question. It arises as a small, fleshy belly about the size of M. PPB, by a tendinous sheet or sheath on the Intumescentia of the humerus (cranial surface of the head of the humerus). The tear-drop shaped belly gives rise to a slender tendon that curves across the surface of $M$. biceps brachii to join $M$. PPB at its distal end.

\section{M. supracoracoideus (Figs 10, 13, 14 : SUP)}

A bipennate muscle arising fleshy from the cranial half of the sternal carina (two-fifths in USNM 504983) and from the caudoventral surface of the coracoclavicular membrane, and by semitendinous fibres from the craniomedial surface of the sternum. The fibres converge on a stout tendon that passes through the triosseal canal to insert on the Tuberculum dorsale of the humerus. Most of the tendon of insertion is concealed distally by the belly of $\mathrm{M}$. deltoideus minor.

G. stellata: As in G. immer.

Pelecanoides garnoti: This muscle has a deep and a superficial layer that are easily separable. The former is fan-shaped and inserts on the Crista pectoralis, the latter is bipennate and inserts by a very stout tendon on the Caput humeri 


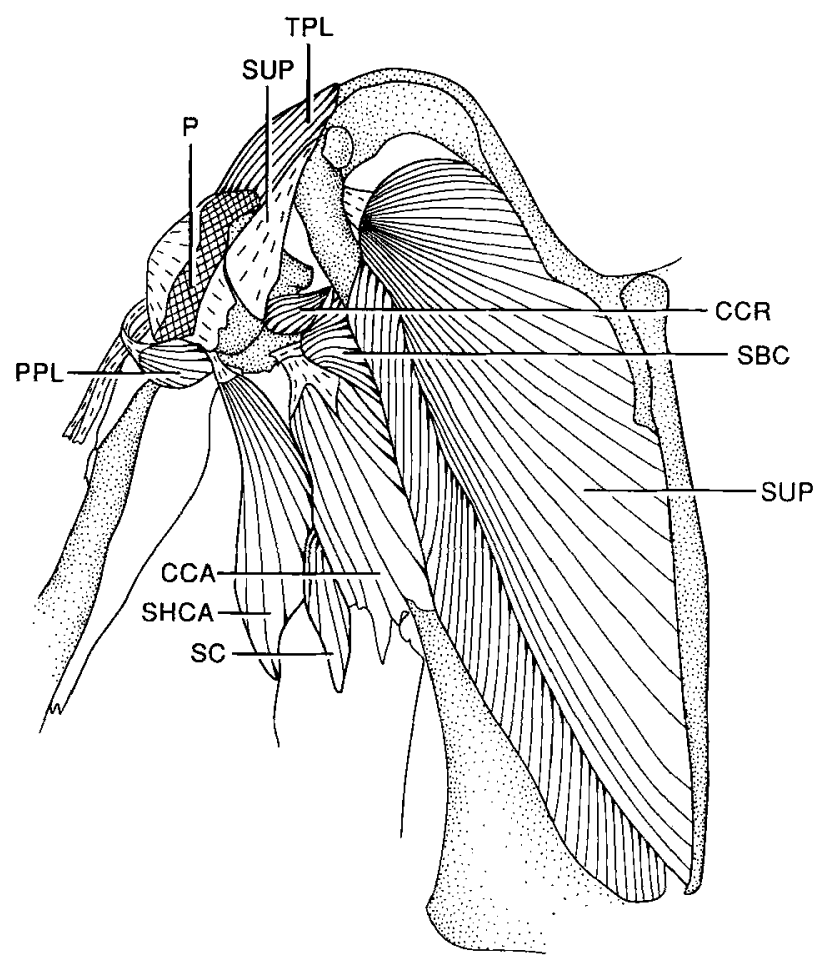

Figure 14. Second layer of extrinsic ventral muscles of the forelimb, Pelecanoides garnoti.

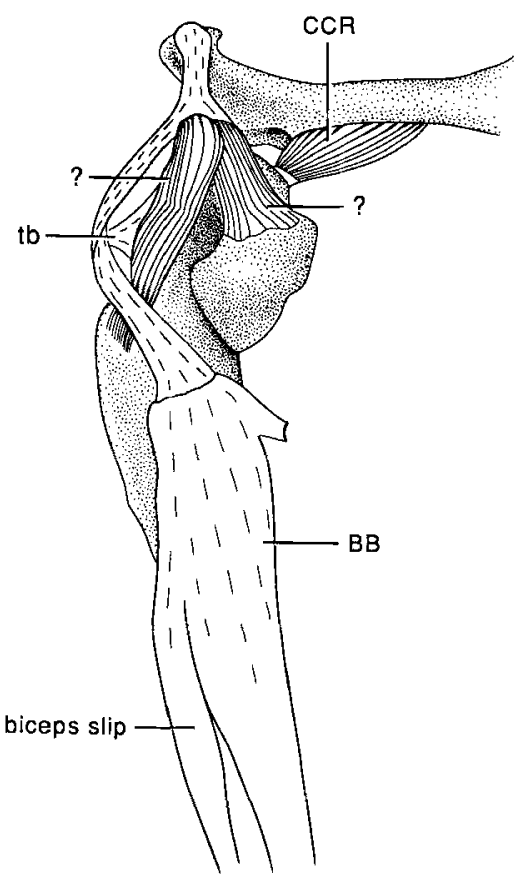

Figure 15. Mystery muscles of the humeral head, Gavia immer. 
and Tuberculum dorsale of the humerus. The origin is from the entire length of the sternal carina and the sternum, and semitendinously from the distal end of the ventral surface of the coracoid and the caudal surface of the clavicle.

\section{M. tensor propatagialis longus et brevis (Figs 11, 12, 14)}

Consists of a single, strap-shaped belly, arising by semitendinous fibres on the dorsal surface of the dorsal end of the scapula (there is no origin from the coracoid). It passes distad towards the brachium, giving rise to a tendon, Tendo longa, which forms the leading edge of the patagium. Tendo longa is joined at its proximal end by the tendons of $\mathrm{Mm}$. pectoralis pars propatagialis longus and cucularis capitis pars propatagialis.

The belly of the biceps slip of $\mathrm{M}$. biceps brachii is partially fused with the caudal border of Tendo longa.

A narrow tendon arises from the caudal border of the belly of $M$. tensor propatagialis longus et brevis, passing parallel to the humerus to insert into the fascia covering the proximal surface of the forearm, proximal to the insertion of the biceps slip.

$G$. stellata: The muscle is a single belly arising fleshy from the dorsolateral surface of the clavicle (not on the scapula) near its junction with the coracoid. It gives rise to Tendo longa as described for G. immer (except it is not joined by $\mathrm{Mm}$. pectoralis and cucularis).

Pelecanoides garnoti: This is a single, unipennate or fan-shaped belly; it arises semitendinously from the dorsal surface of the clavicle. Tendo longa arises from the surface of the belly. A second tendon arises from the caudal border of Tendo longa and passes roughly parallel to the humerus to insert onto the aponeurosis covering the proximal surface of the forearm. It also anchors tendinously to the surface of $M$. extensor metacarpi radialis, and then sends a branch distad that inserts as part of the aponeurosis covering the musculature on the dorsal surface of the forearm. Tendo longa passes into the patagium and crosses the ulnocarpometacarpal joint with a large sesamoid, and inserts on the caudoventral surface of the base of the alular digit. It sends out a tiny slender branch to the dorsal surface of the distal end of the major metacarpal. On the ventral surface, near where the arm and hand join, Tendo longa sends out a wide branch that anchors on the Os radiale, the proximal end of the carpometacarpus, and the base of the alular digit (insertion not illustrated). It also sends a branch to M. adductor alulae.

\section{$M$. deltoideus major (Figs 1, 2, 10: DMA)}

A single belly arising by semitendinous fibres from the dorsal surface of the dorsal end of the clavicle and from the acromion of the scapula. A deeper layer arises from the head of the coracoid. A tendinous band anchors the belly proximomedially to the shaft of the scapula at an acute angle. The slightly fanshaped belly passes distad to insert by an aponeurosis on the dorsolateral surface of the Crista pectoralis of the humerus.

G. stellata: As in G. immer; there is also a ligamentous anchor from the deep surface of the belly to the humeroscapular ligament. I found no evidence of a coracoidal origin, however.

Pelecanoides garnoti: This muscle is greatly reduced. It is a small, strap-shaped belly lying deep to the bellies of $\mathrm{Mm}$. humerotriceps and tensor patagii longus et 
brevis. It lies next to $M$. deltoideus minor and like it, partially overlies the tendon of insertion of $M$. supracoracoideus. It arises by fleshy fibres from the acromion of the scapula, and by fleshy fibres dorsally and a thin, semitendinous sheet ventrally from the tip of the clavicle. It inserts by a thin aponeurosis on the dorsal surface of the humeral shaft, just distal to the head of the humerus. The homology of this muscle to M. deltoideus major is in question.

\section{M. delloideus minor (Figs 5, 10, $13: \mathrm{DMI}$ )}

A narrow (15 mm wide at origin in G. immer CM 2320), strap-shaped muscle lying superficial to the tendon of insertion of $M$. supracoracoideus on the head of the humerus. It arises by semitendinous fibres from the lateral surface of the dorsal end of the clavicle, inside the triosseal canal, and from the acromion of the scapula. There is no coracoidal origin. It narrows as it passes fleshy around the head of the humerus to insert fleshy and tendinously on the craniodorsal surface of the head of the humerus and the Crista pectoralis. It is about $6 \mathrm{~mm}$ wide at its insertion.

G. stellata: 'The origin is $15 \mathrm{~mm}$ wide from the lateral surface of the dorsal end of the clavicle. The insertion is on the ventral surface of the head of the humerus, and on the Crista pectoralis. There is no origin from the acromion. The insertion is about $7 \mathrm{~mm}$ wide.

Pelecanoides garnoti: The origin is fleshy from the lateral surface of the scapular head and the dorsal end of the clavicle.

\section{M. triceps brachii}

M. scapulotriceps (Figs 1, 2, 5, 13: TS) is a long, spindle-shaped belly arising by semitendinous fibres from the dorsal surface of the head of the scapula and from the ligament between the head of the scapula and the Fossa pneumotricipitalis of the humerus. There is no "furcular" origin (Sanders, 1967:150). It is anchored on its deep surface to the proximal end of the shaft of the scapula by a dense, triangular tendinous sheet. The belly is covered with a dense aponeurosis in its distal two-thirds. The belly extends nearly the length of the humerus and gives rise to a narrow tendon, which passes over the Sulcus $m$. scapulotricipitis of the humerus to insert on the Processus cotylaris dorsalis of the ulna. A humeral anchor (ha) arising on the deep surface of $M$. scapulotriceps fuses with the tendon of insertion of $\mathrm{M}$. latissimus dorsi caudalis - see description under that muscle.

G. stellata: As in $G$. immer.

Pelecanoides garnoti: This is a bipennate muscle arising by tendinous, semitendinous and fleshy fibres on the dorsolateral surface and ventral border of the scapular head and from the head of the coracoid, from the dorsal lip of the Caput humeri, and from the dorsal tip of the clavicle. A smaller slip arises by a short tendon on the caudodorsal surface of the humeral shaft (in UMMZ 225240 this slip is fused with M. humerotriceps and appears to be part of that muscle). A flat, tendinous anchor extends from the deep surface of the muscle to the shaft of the humerus, deep to M. deltoideus major. At its tip this anchor is fused with the tendon of insertion of $\mathrm{M}$. latissimus dorsi cranialis and caudalis. The fusion is not extensive. The muscle is not covered with an aponeurosis, and inserts as described below under $M$. humerotriceps.

M. humerotriceps (Figs 5, 7, 12, $13: \mathrm{TH}$ ) is a long, bipennate muscle arising by 


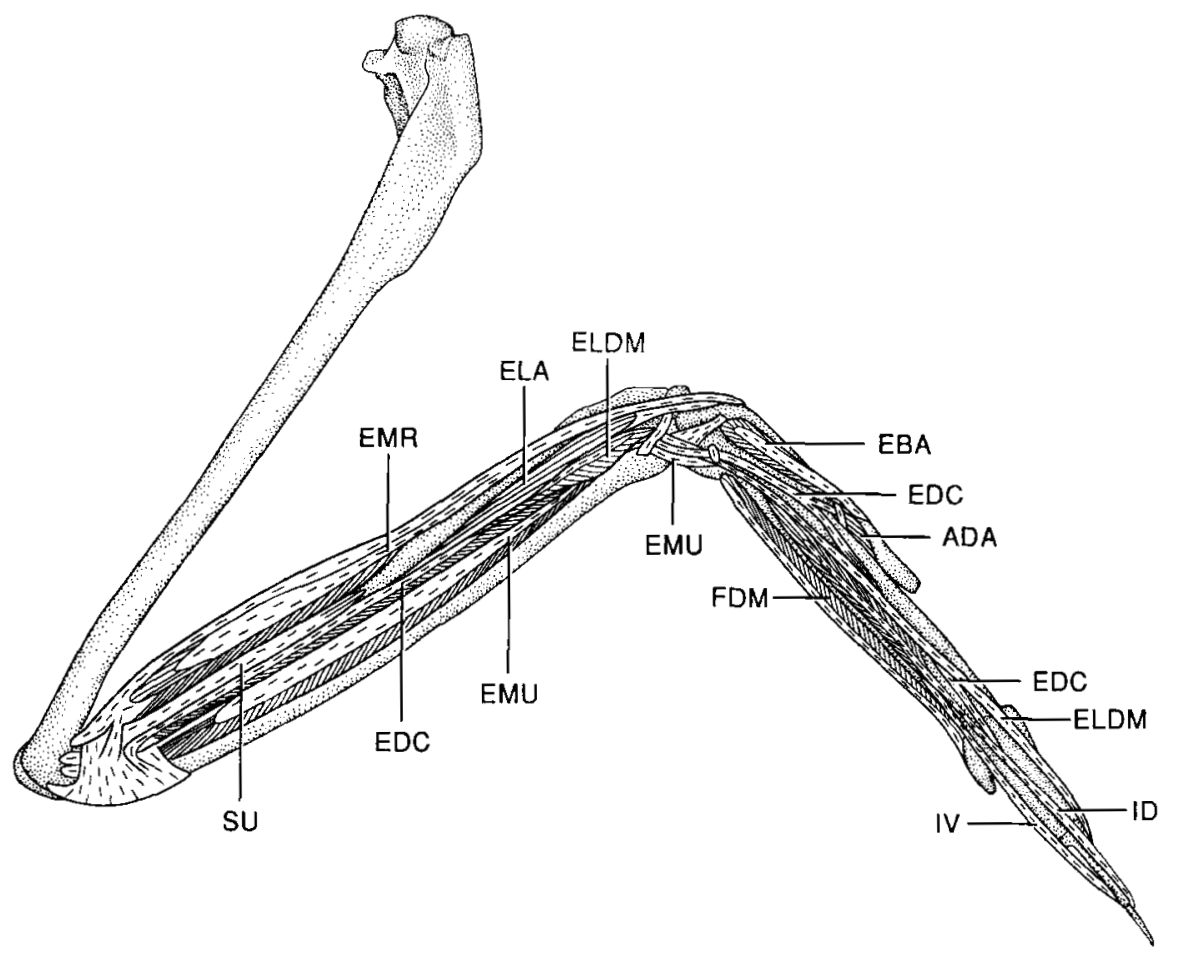

Figure 16. Superficial intrinsic dorsal muscles of the forelimb, Gavia immer.

semitendinous fibres on the ventral border of the ventral (large) Fossa pneumotricipitalis of the humerus as well as within that fossa; from the dorsal border of the fossa, and from within the dorsal (small) Fossa pneumotricipitalis and on the Tuberculum dorsale of the humerus. The fibres of the ventral origin surround the tendon of insertion of $\mathrm{M}$. scapulohumeralis caudalis. The muscle also arises by semitendinous fibres from most of the length of the caudal surface

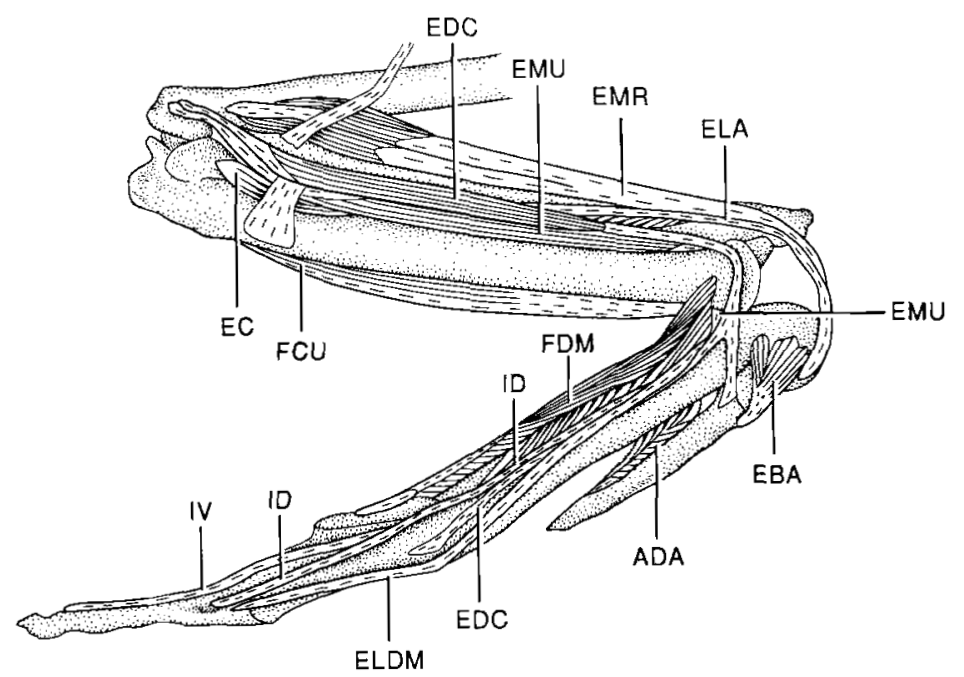

Figure 17. Superficial intrinsic dorsal muscles of the forelimb, Pelecanoides garnoti. 
of the shaft of the humerus. The fibres of the various origins converge on a large central tendon to make the muscle unipennate to the distal end of the humerus. The muscle inserts by a stout tendon on the olecranon of the ulna.

$G$. stellata: As in $G$. immer. The tendons of insertion of $\mathrm{Mm}$. TS and $\mathrm{TH}$ are separate (contra Sanders, 1967:157), but are connected by fascia.

Pelecanoides garnoti: This is a long, bicipital muscle extending the entire length of the humerus. It arises fleshy and semitendinously in the Fossa pneumotricipitalis of the humerus and from the 'dorsal tricipital impression' (this is where the dorsal Fossa pneumotricipitalis would be if present) just distal to the Caput humeri. Fibres continue to arise on the entire length of the humerus. The two heads converge in the proximal one-quarter of the humerus, and the fibres of the common belly insert at an acute angle onto its common tendon of insertion with M. scapulotriceps. M. humerotriceps also has its own tendon of insertion, separate from the common one: this tendon arises on the ventral surface of M. humerotriceps as an aponeurosis and passes parallel to the other tendon down the length of the humerus. The tendinous insertions are on the olecranon process of the ulna.

\section{$M$. biceps brachii (Figs 1, 11-13, 18: BB)}

A slender spindle-shaped belly arising by a tendon $6 \mathrm{~mm}$ wide on the head of the coracoid. A tendinous band (tb in Fig. 15) anchors the tendon of origin to the ventral surface of the Crista pectoralis. The tendon passes deep to the insertion of $\mathrm{M}$. pectoralis thoracicus and continues into the arm; after $58 \mathrm{~mm}$ (59 $\mathrm{mm}$ in $G$. immer USNM 504983) it gives rise to the slender belly and to the biceps slip. The belly of $\mathrm{M}$. biceps brachii passes three-quarters the length of the humerus (half in G. immer USNM 504983) and gives rise to the tendon of insertion, which passes between $\mathrm{Mm}$. extensor metacarpi radialis and brachialis to insert on the Tuberculum bicipitale of the caudal surface of the proximal end of the radius. A second branch inserts on the Tuberculum bicipitale of the ulna.

The fleshy belly of the biceps slip is fused distally with the caudal border of Tendo longa, and is anchored to the Crista pectoralis by an elastic tendinous sheet. The belly extends two-thirds the length of the humerus (half in $G$. immer USNM 504983), giving rise to a tendon that passes superficial to the belly of M. extensor metacarpi radialis and is anchored to the surface of that muscle at its proximal end. The tendon fans out slightly to insert on the aponeurosis antebrachialis dorsalis on the dorsal surface of the forearm.

Two small, stout, strap-shaped bellies (Fig. 15) arise side by side on the head of the coracoid near the tendon of origin of M. biceps brachii. The more medial of the two arises on the humero-coracoidal ligament. The lateral belly inserts by tendinous fibres, the medial belly by fleshy fibres, on the ventral surface of the Crista pectoralis of the humerus. The identity of these small bellies is a mystery. The more lateral of the two may be an 'accessory' biceps (unlike that mentioned in George \& Berger, 1966:330), but the homology of the medial one is quite uncertain. Only the medial belly is present in $G$. immer USNM 504983.

$G$. stellata: As in $G$. immer. The tendon of origin is $4 \mathrm{~mm}$ wide. Neither of the small, strap-shaped bellies is present.

Pelecanoides garnoti: The muscle arises by a slender tendon from the head of the coracoid. There is no tendinous band and no biceps slip. It is a small muscle, extending less than one-quarter the way down the humeral shaft, before giving 


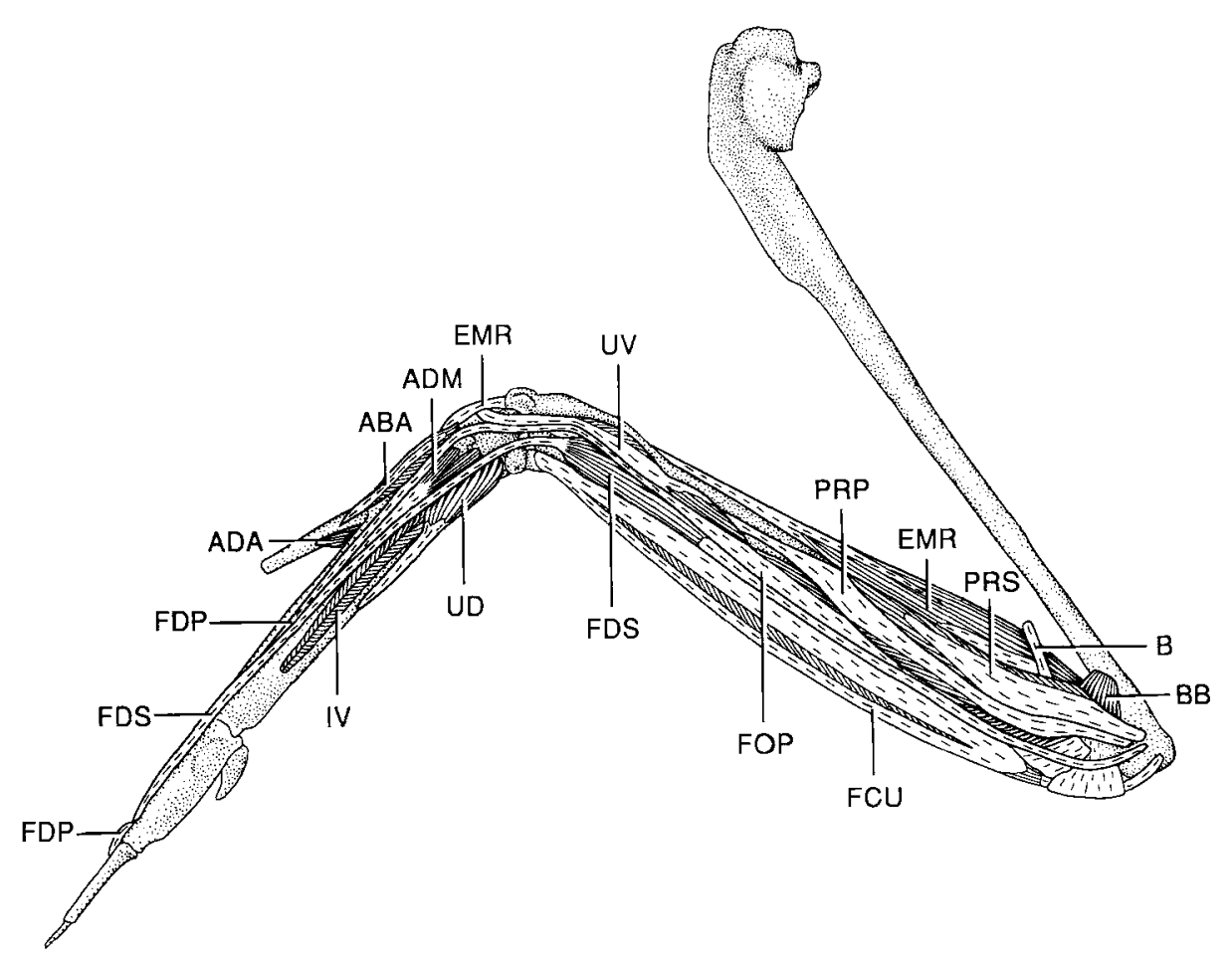

Figure 18. Superficial intrinsic ventral muscles of the forelimb, Gavia immer.

rise to the slender tendon which bifurcates to insert on the radius and ulna. Two ligaments extend from the coracoidal head to the Sulcus ligamentus transversus; these occupy the same relative positions as the two unidentified muscles in Gavia. The lateral ligament has both smooth and skeletal muscle fibres adhering to it.

M. expansor secundariorum (Fig. 19: ES)

Reported as absent in loons (Beddard, 1898:387). It is present, however, as a subcutaneous, trapezoidal, muscle arising on the tendon of insertion of M. scapulotriceps and on the subcutaneous fascia of the elbow region. The fibres cannot be discerned. The muscle inserts on the bases of the first five secondaries.

$G$. stellata: As in $G$. immer, but inserting on the first seven secondaries.

Pelecanoides garnoti: The muscle is fibrous, and arises as a dentate muscle on the humero-ulnar pulley and from the tendinous sheath surrounding the tendon of origin of M. FCU. The 'teeth' insert on the first five secondaries. The humeroulnar pulley is a tendinous triangle that ensheathes the tendon of origin of M. flexor carpi ulnaris. It arises on the humerus near the Tuberculum supracondylare ventrale and anchors on the ventral surface of the proximal end of the ulna.

$M$. brachialis (Figs 12, 18, 19, $21: \mathrm{B}$ )

A rectangular muscle arising fleshy in the Fossa $\mathrm{m}$. brachialis of the humerus and inserting fleshy on the cranioventral surface of the proximal end of the ulna (Depressio $\mathrm{m}$. brachialis of the ulna).

$G$. stellata and Pelecanoides garnoti: As in $G$. immer. 


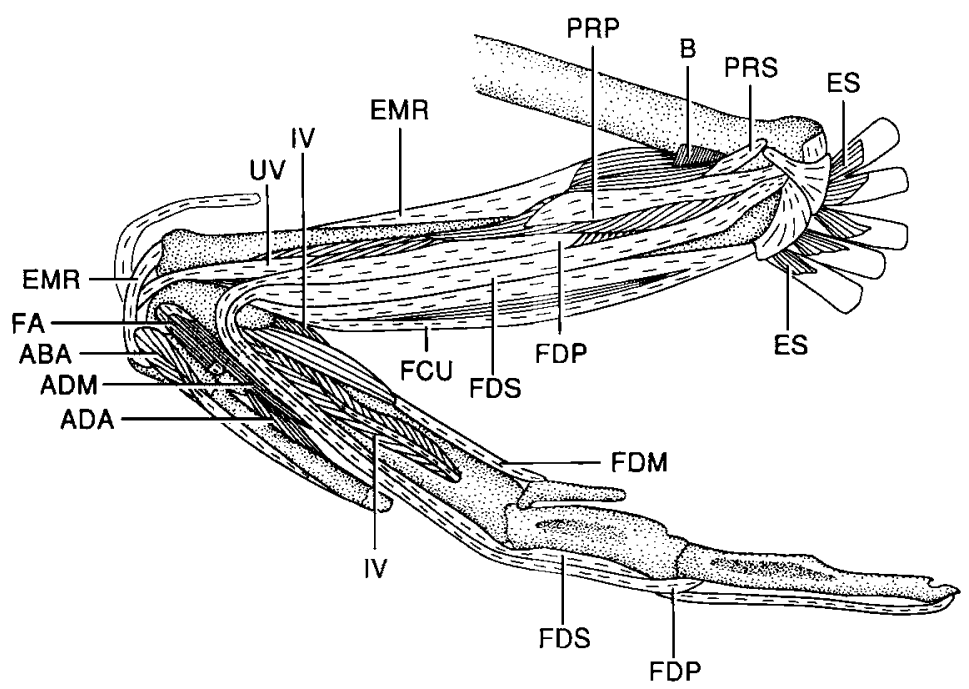

Figure 19. Superficial layer of intrinsic ventral muscles of the forelimb, Pelecanoides garnoti.

\section{M. pronator superficialis (Figs 18, 19: PRS)}

An irregularly spindle-shaped muscle arising by a stout tendon from the Tuberculum supracondylare ventrale of the humerus, slightly proximal and partly superficial to the origin of $\mathrm{M}$. pronator profundus. The tendon of origin fans out to cover most of the ventral surface of the muscle as an aponeurosis and is continuous distally with the humerocarpal band covering $\mathrm{Mm}$. flexor digitorum superficialis and flexor carpi ulnaris. The muscle extends about one-third of the length of the radius (two-fifths in G. immer USNM 504983) and inserts by tendinous fibres along the cranioventral surface of the proximal one-third of that bone.

G. stellata: As in G. immer CM 2320, but extends nearly half of the length of the radius. A slender, tendinous strap extends from the tendon of origin (proximal end, caudal surface) proximad, superficial to $\mathrm{M}$. pronator profundus, to join the proximal end of the humerocarpal band. This keeps the tendon of origin of $\mathrm{M}$. pronator superficialis at an angle of about 130 degrees when the wing is folded.

Pelecanoides garnoti: Very small relative to $\mathrm{M}$. pronator profundus. It is an irregularly spindle-shaped muscle arising by a moderately well-developed tendon from the Tuberculum supracondylare ventrale of the humerus. This tendon does not cover the belly as an aponeurosis. The muscle extends scarcely one-quarter the length of the radius, on which it inserts by tendinous fibres along the cranioventral surface.

\section{M. pronator profundus (Figs 18, 19: PRP)}

A unipennate muscle lying partly deep to $M$. pronator superficialis on the ventral surface of the forearm. It arises by a stout tendon from the Tuberculum supracondylare ventrale of the humerus, distal and partly deep to the origin of M. pronator superficialis, proximal and partly deep to the origin of $\mathrm{M}$. flexor digitorum superficialis. It is covered for most of its length by an aponeurosis 
formed by its tendon of origin. The muscle extends the length of the radius and inserts by fleshy and semitendinous fibres on the ventral surface of the length of that bone.

G. stellata: As in $G$. immer. In its distal half the muscle is covered by the humerocarpal band. The latter band (see description under M. flexor digitorum superficialis) also attaches to the ventral surface of the distal half of the radius. The dense ligamentous tissue covering the ventral surface of the manus is also part of this band.

Pelecanoides garnoti: As in G. immer except that it does not arise on the Tuberculum supracondylare ventrale, it arises on the ventral epicondyle, as nearly as can be determined considering homology problems with Baumel $\ell$ al. (1979). The tendon of origin passes deep to the tendon of origin of the humeroulnar pulley. The insertion is primarily fleshy on the proximal half of the radius, and tendinous for the remainder of the length of the radius.

\section{M. flexor carpi ulnaris (Figs 17-19: FGU)}

The most caudally situated muscle on the ventral surface of the forearm. It arises by a very stout tendon from the Proc. flexorius of the humerus and passes through a ligamentous sling (humero-ulnar pulley) to give rise to a slender belly that passes the length of the forearm and inserts on the caudal surface of the Os carpi ulnare. The humerocarpal band covers the ventral surface of $\mathrm{M}$. flexor carpi ulnaris, inserting near the base of the secondaries. See description under M. flexor digitorum superficialis, below.

$G$. stellata: As in $G$. immer.

Pelecanoides garnoti: As in Gavia. Most of the ventral surface of the muscle is covered by an aponeurosis, in addition to the humerocarpal band. The tendon of insertion is ossified at its distal end.

\section{M. flexor digitorum superficialis (Figs 18, 19 : FDS)}

Lies caudal to the two pronators on the ventral surface of the forearm. It arises by a stout tendon on the ventral epicondyle of the humerus, distal and partly superficial to the origin of $\mathbf{M}$. pronator profundus. The tendon continues distad for more than three-quarters of the length of the forearm before giving rise to the fleshy belly. The tendon fans out to form the humerocarpal band, which covers the ventral surface of $\mathrm{M}$. flexor carpi ulnaris as well as the dorsal surface of that muscle, attaching on the caudal surface of the shaft of the ulna for most of its length as well as to the bases of the secondaries. The tendon of origin of $\mathrm{M}$. flexor digitorum superficialis fans out to ensheathe the belly of the muscle, concealing the fibres from view. At the distal end of the forearm the belly gives rise to the tendon of insertion, which passes around the cranial surface of the Os ulnare and is held in place there by a ligament. The tendon enters the manus and passes over the articulation between the carpometacarpus and major digit with a $3 \mathrm{~mm}$ sesamoid shared with the tendon of insertion of M. flexor digitorum profundus. The tendon ensheathes that of $\mathbf{M}$. flexor digitorum profundus and is tightly bound to the cranioventral surface of the proximal end of the 2 nd phalanx of the major digit.

The humerocarpal band attaches at the base of the secondaries. It is particularly dense at the distal end of the forearm in the region of the ulnocarpal joint, and at the base of the first five secondaries. The band passes over 
the dorsal articular surface and anchors on the Cotyla dorsalis of the ulna as well as on the proximodorsal and cranioventral surface of the carpometacarpus.

$G$. stellata: As in $G$. immer, except the tendon of origin extends just threequarters of the length of the forearm before giving rise to the fleshy belly.

Pelecanoides garnoti: Arises at a point just proximal to the Proc. flexorius-one could say, the ventral surface of same. The origin is distal but not superficial to the origin of $\mathbf{M}$. pronator profundus. The tendon of origin passes half the length of the forearm before giving rise to the belly, which is almost completely covered by a dense aponeurosis formed by the tendon of origin. The tendon of insertion is tightly bound to the 2nd phalanx of the major digit as in Gavia but also sends a smaller branch nearly to the very tip of the 2 nd phalanx. Otherwise as in Gavia. The humerocarpal band is as described for Gavia.

\section{M. flexor digitorum profundus (Figs 18, 19: FDP)}

A long, slender, bipennate muscle arising fleshy on either side of M. brachialis on the ventral surface of the ulnar shaft, and by tendinous fibres from the proximal two-thirds of the ulnar shaft. In its distal third the belly passes superficial to $\mathrm{M}$. ulnometacarpalis ventralis; some of the fibres from its dorsal surface attach to the ventral surface of that muscle in Gavia immer CM 2320 R but not L nor in $G$. immer USNM 504983. The belly passes seven-eighths the way down the forearm and narrows to a tendon which is held in place against the distal end of the ulna by a dense retinaculum. The tendon passes across the dorsal surface of the minor metacarpal and around the Processus intermetacarpalis, against which it is held by a retinaculum, whence it passes along the cranial edge of the major metacarpal to insert at the base of the 2nd phalanx of the major digit. It passes over the articulation between the carpometacarpus and major digit with a sesamoid as described under $\mathbf{M}$. flexor digitorum superficialis. A few caudal fibres of $\mathbf{M}$. flexor digitorum profundus attach by a tiny tendon to a neighbouring blood vessel in $G$. immer CM $2320 \mathrm{R}$.

$G$. stellata: As in $G$. immer except it passes three-quarters, not seven-eighths, the length of the forearm before becoming entirely tendinous. Also, only a small bundle of fibres arises on the side of the ulna that is caudal to $\mathrm{M}$. brachialis; most of the origin is cranial to $\mathrm{M}$. brachialis. This bundle has a tendinous constriction that joins it to the body of the muscle distad.

Pelecanoides garnoti: As in Gavia except the origin is cranial to the origin of M. brachialis but not caudal, and is semitendinous. No fibres attach to M. ulnometacarpalis ventralis. The tendons of $\mathrm{Mm}$. flexor digitorum superficialis and flexor digitorum profundus pass over the base of the first phalanx with a sesamoid.

\section{M. extensor metacarpi radialis (Figs 16-19: EMR)}

Has two heads of origin. Pars ventralis arises by semitendinous fibres from the ventral surface of the Processus supracondylaris dorsalis of the humerus. Pars dorsalis arises by tendinous and semitendinous fibres from the dorsal surface of the Processus supracondylaris dorsalis of the humerus. Pars dorsalis is composed of two distinct but fused bellies partially separable for their entire length including the tendons. In addition, there is a tendinous anchor from the proximocranial surface of pars dorsalis that passes superficial to M. supinator and fans out to attach broadly on the proximodorsal surface of the ulna and on 
the surface of the tendon of insertion of M. scapulotriceps (not shown in the figure). The anchor to $M$. scapulotriceps is not present in G. immer USNM 504983.

The two heads fuse near their proximal ends and continue distad as a common, bipennate belly about half-way down the forearm before becoming entirely tendinous. The common tendon of insertion narrows distally and passes through a groove at the distal end of the radius, around the Os radiale and the proximal end of the carpometacarpus, to insert on the Processus extensorius of the latter.

The biceps slip is anchored to the dorsal surface of $\mathbf{M}$. extensor metacarpi radialis. See description under $M$. biceps brachii.

G. stellata: Neither head is separable into two bellies. Pars ventralis is larger but shorter than pars dorsalis. There is no anchor on the tendon of M. scapulotriceps.

Pelecanoides garnoti: As in G. immer except pars dorsalis is not separable into two parts and pars ventralis has two tendinous points of origin from the Proc. supracondylaris dorsalis. The dorsal and ventral bellies are separate, and both pass three-quarters of the way down the forearm before becoming entirely tendinous. Near its insertion the tendon is partly ensheathed by the distal end of Tendo longa. There is no biceps slip to anchor on M. extensor metacarpi radialis. See reference to $M$. extensor metacarpi radialis under description for M. tensor propatagii longus et brevis.

\section{M. extensor digitorum communis (Figs $16,17:$ EDG)}

A slender, unipennate muscle arising by a stout tendon on the dorsal epicondyle of the humerus in common with $M$. supinator. The belly passes the length of the forearm before becoming entirely tendinous. The tendon passes through a tendinal sulcus at the distal end of the ulna and into the manus. It is bound to the dorsal surface of the alular metacarpal by a retinaculum, after which it passes distad about $20 \mathrm{~mm}$ and bifurcates. The shorter branch, which is slightly wider than the long branch, inserts on the caudal surface of the proximal end of the alula. The longer branch passes distad in a tendinal sulcus of the major metacarpal, passing deep to $\mathbf{M}$. extensor longus digiti majoris. It inserts on the craniodorsal surface of the proximal end of the first phalanx of the major digit. M. extensor digitorum communis is loosely covered by a dense aponeurosis over its entire length. This aponeurosis originates on the surface of $\mathrm{M}$. supinator and passes over the surface of $\mathrm{Mm}$. extensor digitorum communis and extensor metacarpi ulnaris to attach at the base of the secondaries on the dorsal surface of the ulna. Cranially, it is attached just cranial to M. extensor digitorum communis on the caudal surface of the radius.

$G$. stellata: As in G. immer.

Pelecanoides garnoti: As in $G$. immer, but the origin is not with $\mathrm{M}$. supinator, which is absent, and the belly passes two-thirds of the length (three-quarters in UMMZ 225240) of the forearm before becoming entirely tendinous.

\section{$M$. extensor metacarpi ulnaris (Figs 16, 17 : EMU)}

A spindle-shaped belly situated on the caudodorsal surface of the forearm. It arises by a stout tendon on the dorsal epicondyle of the humerus, just distal to the common origin of $\mathrm{Mm}$, supinator and extensor digitorum communis. It is 


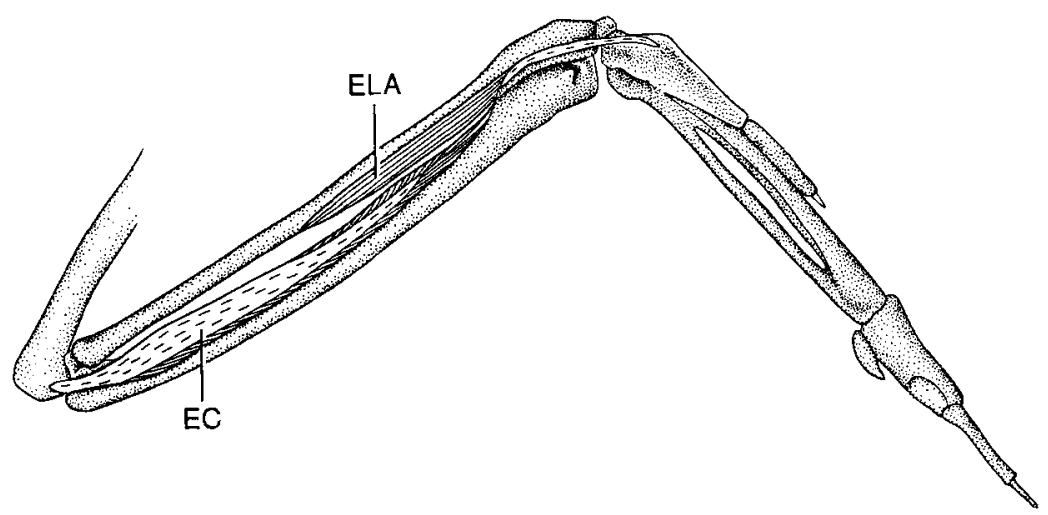

Figure 20. Second layer of intrinsic dorsal muscles of the forelimb, Gavia immer.

covered at its proximal end by an ulnar anchor; this anchor originates partly on M. supinator as described under that muscle, and partly (the distal portion) from the dorsal surface of $\mathrm{M}$. extensor digitorum communis. The belly passes the length of the ulna, becoming entirely tendinous at the distal end of that bone. The stout tendon passes around the dorsal condyle of the ulna and into the manus to insert at the proximal end of the major metacarpal on the caudodorsal surface of that bone.

G. stellata: As in G. immer.

Pelecanoides garnoti: As in Gavia except delete reference to M. supinator. The insertion is deep to the origin of $\mathrm{M}$. interosseus dorsalis on the major metacarpal and thus is not visible superficially.

\section{M. extensor longus alulae (Figs 16, 17, 20, 21 : ELA)}

A narrow, bipennate, bicipital muscle arising by semitendinous fibres from the caudal surface of the central one-third of the shaft of the radius (proximal twofifths in G. immer USNM 504983), the craniodorsal surface of the distal half of the radius, by fleshy fibres from the cranial surface of the proximal quarter of the ulna, and by semitendinous fibres from the ventral surface of the proximal oneeighth of $\mathbf{M}$. ectepicondylo-ulnaris (the origin from the latter is lacking in $G$. immer USNM 504983). The belly passes along the dorsal surface of the radius and narrows to a stout tendon. The tendon passes through a sulcus in the Os radiale and inserts in common with the tendon of $\mathbf{M}$. extensor metacarpi radialis on the craniodorsal surface of the Processus extensorius of the carpometacarpus.

$G$. stellata: As in $G$. immer, but the radial origin is from the distal half of the caudodorsal surface of the radius.

Pelecanoides garnoti: Arises fleshy and semitendinously primarily on the cranial surface of the proximal third of the shaft of the ulna. There may have been some fleshy fibres originating on the caudal surface of the radius. There is no origin from M. ectepicondylo-ulnaris.

\section{M. extensor longus digiti majoris (Figs 16, 17 : ELDM)}

A narrow, bipennate muscle arising by tendinous fibres from the caudal surface of the radius in the distal quarter of that bone. It passes through a ligamentous sling (extending between the Tuberculum retinaculi of the ulna and 
the distal end of the radius), around the dorsal condyle of the ulna and into the manus. The stout tendon passes along the dorsal surface of the major metacarpal, superficial to the tendon of $\mathbf{M}$. extensor digitorum communis, to insert on the proximodorsal surface of the 2nd phalanx of the major digit. A distal head is present in $G$. immer USNM 504983 as a tendon with no fleshy fibres. The tendon arises at the base of the insertion of $\mathbf{M}$. extensor metacarpi ulnaris.

G. stellata: As in $G$. immer. A few fibres extend from the caudal surface of the major digit of the carpometacarpus near the point where the distal head joins M. ELDM; these fibres do not belong to any muscle. The distal head is a unipennate belly arising fleshy on the caudodorsal surface of the major metacarpal. It narrows to a slender tendon that joins the tendon of insertion of M. ELDM one-quarter of the way down the major metacarpal, and fuses with that tendon. Some of the fibres of the muscle also join the tendon of M. extensor longus digiti majoris, distal to the point where the two tendons fuse.

Pelecanoides garnoti: As in G. immer except the origin is from the distal one-third of the radius. In UMMZ 225241 (but not 225240) there is evidence of the distal head as well in a very slender tendon that evidently originated on the dorsal surface of the major metacarpal to join the tendon of M. ELDM. The origin was severed, however. The tendon lacks fleshy fibres.

\section{M. supinator (Fig. 16:SU)}

Situated on the cranial surface of the radius, deep to M. extensor metacarpi radialis. It arises by a stout tendon on the dorsal epicondyle of the humerus, in common with the tendon of origin of $\mathrm{M}$. extensor digitorum communis. The belly is bound in place on the radius at its proximal end by an anchor passing from its dorsal surface, superficial to the proximal end of $\mathrm{Mm}$. extensor digitorum communis and extensor metacarpi ulnaris, and attaching on the dorsal surface of the ulna. The bulky belly passes nearly half of the length of the radius and inserts by semitendinous fibres on the caudodorsal, dorsal and craniodorsal surface of that bone (no caudodorsal fibres of insertion in $G$. immer USNM 504983). The belly is covered by a dense aponeurosis for most of its length.

G. stellata: As in G. immer but the craniodorsal fibres pass two-fifths of the length of the radius, and the dorsal fibres a quarter. There are no caudodorsal fibres.

Pelecanoides garnoti: M. supinator is absent, but see description under M. ectepicondylo-ulnaris.

\section{M. ectepicondylo-ulnaris (Figs 17, $20: \mathrm{EC}$ )}

The deepest muscle on the dorsal surface of the forearm. It arises by a stout tendon shared with $M$. extensor metacarpi ulnaris from the dorsal epicondyle of the humerus, and the two bellies are tightly fused in their proximal one-eighth. The tendon of origin fans out to form a dense aponeurosis over the elongate, fanshaped belly. The muscle inserts semitendinously on the caudodorsal surface of nearly the entire length of the ulna.

G. stellata: As in G. immer.

Pelecanoides garnoti: The muscle has three points of origin: one by a stout tendon on the dorsal epicondyle of the humerus in common with $\mathrm{M}$. extensor 
digitorum communis, one by a lighter, translucent tendon from the dorsal cotyla of the ulna-this tendon sends a branch to anchor on the distal border of the dorsal cotyla - and by a tendon from the craniodorsal surface of the dorsal condyle of the humerus. The three tendons converge to form a very dense aponeurosis covering most of the surface of the muscle. The tendinous contribution from the dorsal epicondyle has a slender, bony spur embedded in it. The bipennate belly inserts on the caudal surface of the proximal half of the ulnar shaft. It is possible that part of this tendinous mass represents all that is left of M. supinator, e.g. the tendinous origin from the dorsal epicondyle in common with $\mathrm{M}$. extensor digitorum communis.

\section{M. ulnomelacarpalis ventralis (Figs 18, 19:UV)}

A bulky, irregularly fan-shaped muscle arising on the distal quarter of the ventral surface of the shaft of the ulna between Mm. pronator profundus and flexor digitorum profundus, caudally; cranially, a second group of semitendinous fibres arises farther distally on the shaft of the ulna. Most of the dorsal and ventral surface of the muscle are covered by a dense aponeurosis. As the belly approaches the distal end of the forearm the caudal group of fibres splits superficially into two fibre masses, which narrow and fuse once again to give rise to the tendon of insertion (not so in G. immer USNM 504983, in which the cranial and caudal groups fuse at the distal end of the ulna). This tendon passes around the $\mathrm{Os}$ radiale, then underneath the tendon of insertion of $\mathrm{M}$. extensor metacarpi radialis to insert on the dorsal surface of the Trochlea carpalis of the carpometacarpus. The cranial fibre group inserts by a tendinous sheet on the ventral condyle of the ulna.

G. stellata: As in G. immer but the origin is fleshy. There is no obvious split of the more dorsal 'caudal' group into two masses. The entire muscle has a tendinous insertion on the Trochlea carpalis of the carpometacarpus.

Pelecanoides garnoti: As in $G$. immer but there is just one fibre mass, arising on the distal fifth (quarter in UMMZ 225240) of the cranioventral surface of the ulna.

\section{M. ulnometacarpalis dorsalis (Figs 18, 19:UD)}

A fan-shaped muscle lying on the caudal surface of the manus. It arises by tendinous fibres from the caudal surface of the Os ulnare and is covered by a dense ligament that invests the ventral surface of the carpometacarpus and the bases of the primaries. The belly extends half-way down the carpometacarpus and inserts into the fascia surrounding the bases of the proximal three primaries.

G. stellata: As in G. immer except there are two tendinous insertions as well-one extending from the distal end of the muscle, across the muscle surface to the Tuberculum retinaculum at the dorsal end of the ulna.

Pelecanoides garnoti UMMZ 225241: The muscle is quite different from that of Gavia. It is nearly parallel fibred and arises semitendinously from the ligamentous tissue surrounding the ulna on the dorsal border at the distal end of the shaft. It inserts by semitendinous fibres on the dorsal surface of the proximal end of the minor metacarpal. In UMMZ 225240 the muscle is absent.

\section{M. interosseus dorsalis (Figs 16, 17 : ID)}

A narrow, bipennate muscle arising fleshy from the dorsal surfaces of the metacarpals surrounding the interosseal space. It becomes entirely tendinous in 
the interosseal sulcus at the distal end of the carpometacarpus. The tendon is held in place by a retinaculum on the distal end of the major metacarpal and passes over the dorsal surface of the major digit to insert on the craniodorsal surface of the base of the last phalanx.

$G$. stellata: As in $G$. immer.

Pelecanoides garnoti: As in Gavia, except there is also a semitendinous origin from the surface of the tendon of insertion of $M$. extensor metacarpi ulnaris.

\section{M. interosseus ventralis (Figs 16-19: IV)}

A narrow, bipennate muscle lying deep to M. ID and arising fleshy from the entire length of the minor metacarpal bordering the interosseal space, and from the distal three-quarters of the major metacarpal. The fibres converge on a central tendon that passes dorsally to emerge on the dorsal surface of the carpometacarpus deep to $\mathbf{M}$. interosseus dorsalis. It passes along the caudal surface of that bone and through a sulcus in the 1st phalanx of the major digit; it is held tightly against the joint between those two bones by a retinaculum. As the tendon passes across the joint between phalanges 1 and 2 of the major digit, it fuses on its dorsal surface with a short ligament originating on the dorsal surface of the distal end of phalanx 1. The tendon inserts on the caudodorsal surface of the base of the last phalanx of the major digit.

G. stellata: As in G. immer.

Pelecanoides garnoti: As in Gavia except it originates from the entire length of both metacarpals. The insertion is half way down (two-thirds in UMMZ 225240) the caudodorsal surface of the second phalanx.

\section{M. abductor alulae (Figs 18, 19: ABA)}

A narrow, bipennate muscle arising by a tendon from the caudoventral edge of the distal end of the tendon of $\mathrm{M}$. extensor metacarpi radialis. It narrows to a tendon and inserts on the proximoventral surface of the alula.

$G$. stellata: As in $G$. immer except the origin is also from the dorsal surface of the alular metacarpal.

Pelecanoides garnoti: As in G. stellata.

\section{M. adductor alulae (Figs 16-19: ADA)}

A small muscle arising fleshy on the cranial surface of the major metacarpal and by a short tendon from the dorsal surface of the distal end of the alular metacarpal. Fibres from the two origins converge on the central tendon to insert on the caudal surface of the innermost alular quill. Some fibres from the tendinous origin insert on the dorsal surface of the proximal half of the alula.

$G$. stellata: Apparently no tendon arises from the alular metacarpal, just a fleshy origin from the cranioventral surface of the major metacarpal and a fleshy insertion on the caudal surface of the alula. No tendons are present. The muscle is parallel fibred.

Pelecanoides garnoti: The origin is semitendinous and there is no 'short tendon'. The insertion is fleshy on the caudal surface of the alula and by a slender tendon at the distal end of the alula, which originates as a branch from Tendo longa. A bundle of muscle fibres extends from the tip of the alula to the distal end of the cranial surface of the major metacarpal. It arises by a slender tendon originating at the distal end of Tendo longa (not illustrated). 


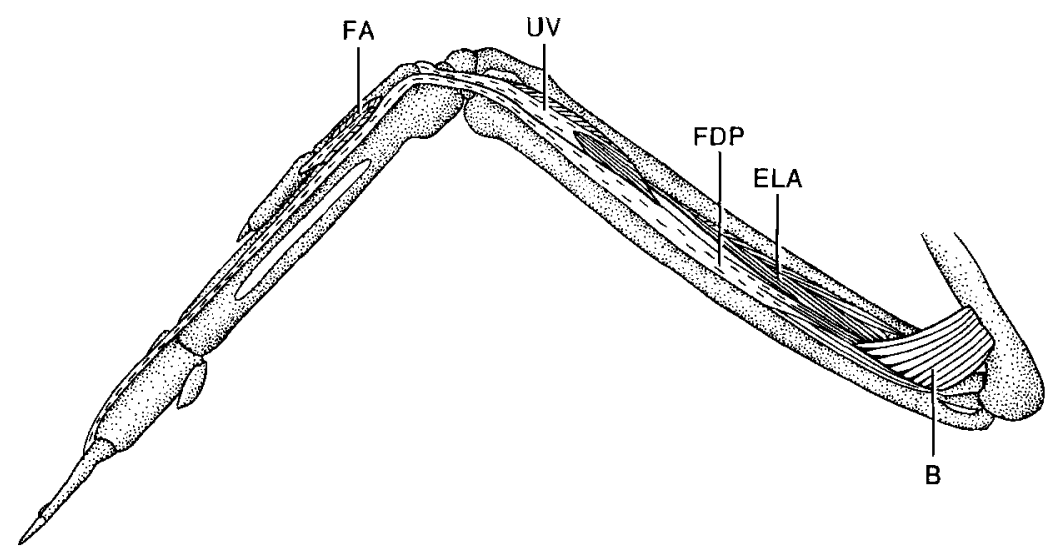

Figure 21. Second layer of intrinsic ventral muscles of the forelimb, Gavia immer.

M. extensor brevis alulae (Figs 16, 17 : EBA)

A narrow, bipennate muscle arising fleshy in a groove on the dorsal surface of the alular metacarpal. It narrows to a tendon and inserts on the craniodorsal corner of the base of the alula.

G. stellata: As in G. immer, but it has two insertions. Fleshy fibres from the caudal edge of the muscle branch off and insert tendinously on the dorsal surface of the alular metacarpal. G. immer USNM 504983 is like G. stellata.

Pelecanoides garnoti: As in $G$. immer, except it is fan-shaped rather than bipennate.

\section{M. flexor alulae (Figs 19, $21:$ FA)}

A narrow, bipennate muscle lying deep to $M$. abductor alulae and arising fleshy on the ventral surface of the alular metacarpal. It inserts by a tendon on the caudoventral surface of the base of the alula.

G. stellata: As in G. immer.

Pelecanoides garnoti: The muscle is very weak; it is strap-shaped and lies between $\mathrm{Mm}$. abductor alulae and abductor digiti majoris.

\section{M. abductor digiti majoris (Figs 18, 19: ADM)}

A bipennate muscle arising by two heads on the ventral surface of the carpometacarpus. The cranial head arises by fleshy fibres on the ventral surface of the Processus intermetacarpalis, the caudal head fleshy from the proximoventral surface of the major metacarpal. The two heads fuse to form a common belly that passes distally and narrows to a tendon. The tendon passes deep to the tendons of $\mathrm{Mm}$. flexor digitorum superficialis and flexor digitorum profundus, to insert on the cranioventral surface of the proximal end of the first phalanx of the major digit. In G. immer USNM 504983 a few fibres of the caudal head arise on the ulno-carpal ligament.

G. stellata: As in G. immer. Fibres occur sporadically on one side or the other of the central tendon for the length of the carpometacarpus.

Pelecanoides garnoti: As in G. immer except the caudal head is weak. In UMMZ 225240 a few semitendinous fibres arise on the caudal surface of the base of the alula. 


\section{M. flexor digiti minoris (Figs 16, 17 : FDM)}

A narrow, bipennate muscle arising fleshy on the caudodorsal surface of the entire length of the minor metacarpal. It becomes entirely tendinous at the distal end of the carpometacarpus, inserting on the caudoventral surface of the base of the minor digit.

G. stellata: As in G. immer.

Pelecanoides garnoti: As in Gavia, except the muscle is considerably bulkier at its origin on the ventral surface of the carpometacarpus. It resembles the illustration of M. ulnometacarpalis dorsalis in Gavia.

\section{Dorsal ligament to primaries}

From the dorsal condyle of the ulna and from the dorsal surface of the length of the ulnar shaft, this ligament fans out to the bases of the primaries. A branch passes superficial and cranial to the tendon of insertion of $M$. extensor digitorum communis to attach at the distal end of the dorsal surface of the minor metacarpal. It actually envelops the tendon of $\mathrm{M}$. extensor digitorum communis as it passes cranially, with the deep layer anchoring on the caudal margin of the minor metacarpal. Ventrally, it attaches along the caudal margin of the major metacarpal.

\section{Characters}

\section{(Table 1)}

1. Iliac origin of M. latissimus dorsi caudalis. This muscle arises only on the vertebrae in some birds (Berger, 1953, 1954; George \& Berger, 1966; Owre, 1967; Zusi \& Bentz, 1984); an additional origin on the ilium occurs in Gavia and Pelecanoides; Podilymbus podiceps and other grebes (Sanders, 1967); various penguins (Schreiweis, 1982); tinamous (Hudson, Schreiweis \& Wang, 1972); cathartids (Fisher, 1946); numerous galliforms (Hudson \& Lanzillotti, 1964); Grus (Fisher \& Goodman, 1955; Berger, 1956b); Lari and Alcae (Hudson et al., 1969); Rhynochetus, Pharomachrus mocino, Chloroceryle americana (George \& Berger, $1966: 291)$. Gadow \& Selenka (1891:227) noted this origin in Gavia as well. Pars caudalis arises on the ilium and the synsacrum in Otus asio and on the dorsal vertebrae, synsacrum and ilium in Chordeiles minor (Gadow \& Selenka, 1891), and on the ilium alone in Polihierax semitorquatus (Berger, 1956a). Many passerines lack pars caudalis (George \& Berger, 1966; Raikow, 1977, 1978; McKitrick, 1985b), as does Columba (George \& Berger, 1966:288).

2. Gap between origin of $M$. latissimus dorsi cranialis and caudalis. The two parts may be continuous with no evident demarcation between them; they may be clearly separate but with no space or very little space between them; there may be a sizeable gap between them. There is little or no space in Gavia and Pelecanoides; grebes (Sanders, 1967); Aptenodytes and Pygoscelis (Schreiweis, 1982); tinamous (Hudson et al., 1972), Grus (Fisher \& Goodman, 1955; Berger, 1956b), cuckoos (Berger, 1953, 1954) and hummingbirds (Zusi, \& Bentz, 1984). The two origins have a significant gap between them in several species of penguins (Schreiweis, 1982), Anhinga and Phalacrocorax (Owre, 1967), Polihierax semitorquatus (Berger, 1956a), cathartids (Fisher, 1946), Lari and Alcae (Hudson et al., 1969), and in Otus asio, Chloroceryle americana and Procnias nudicollis (George 
\& Berger, 1966:292) and various tyrannids (McKitrick, 1985b). The condition is variable in galliforms (Hudson \& Lanzillotti, 1964).

3. Insertion of $\mathbf{M}$. latissimus dorsi by a humeral anchor. $\mathbf{M}$. scapulotriceps may have a humeral anchor; if so $M$. latissimus dorsi may insert in conjunction with this anchor. This is the case in Gavia and Pelecanoides; Podilymbus podiceps and other grebes (Sanders, 1967); Anhinga and Phalacrocorax (Owre, 1967), tinamous (Hudson et al., 1972); Lari and Alcae (Hudson et al., 1969); Otus asio, Chordeiles minor and Pharomachrus mocino (George \& Berger, 1966:293). Cuckoos lack this condition (Berger, 1953, 1954), as do most other birds presumably (George \& Berger, 1966; Zusi \& Bentz, 1984). The M. scapulotriceps of Grus canadensis has a humeral anchor (Berger, 1956b) but it evidently does not attach with M. latissimus dorsi.

4. Stratification of $\mathrm{M}$. pectoralis pars thoracicus. This muscle may have a deep and a superficial layer, as is the case in Gavia and Pelecanoides; Anhinga (Owre, 1967); Bugeranus, Balearica, Scopus (George \& Berger, 1966:308); "many Ciconiiformes" (Beddard, 1898:79); cathartids (Fisher, 1946); Grus americana (Fisher \& Goodman, 1955) but not Grus canadensis (Berger, 1956b); "some Accipitres, all Tubinares [procellariiforms], Streganopodes [pelecaniforms]" (Kuroda, 1961 : 262), Lari and Alcae (Hudson et al., 1969), and hummingbirds (Zusi \& Bentz, 1984). The condition in penguins is not clear from Schreiswies' (1982) description. Grebes do not have two layers (Sanders, 1967), nor do Phalacrocorax Owre, 1967), galliformes (Hudson \& Lanzillotti, 1964), tinamous (Hudson et al., 1972), Polihierax semitorquatus (Berger, 1956a) or cuckoos (Berger, 1953, 1954). Presumably other birds lack this condition as well (George \& Berger, 1966). Kuroda (1961) suggested that this stratification is related to sailing flight; however sailing does not characterize the flight of loons nor diving petrels.

5. Passage of cranial fibres of $M$. pectoralis thoracicus ventral to sternal carina. The most-cranial fibres pass ventral to the sternal carina and merge with those on the opposite side in the following: Gavia; Podilymbus podiceps and other grebes (Sanders, 1967); tinamous (although not so noted by Hudson et al., 1972), ducks and some galliforms (not noted by Hudson \& Lanzillotti (1964) (George \& Berger, 1966:307). This is not the case in penguins (Schreiweis, 1982:26), Grus (Fisher \& Goodman, 1955; Berger, 1956b), nor Pelecanoides. By implication, presumably the majority of birds lack this condition (Fisher, 1946; Berger, 1953, 1954, 1956a; George \& Berger, 1966; Zusi \& Bentz, 1984).

6. Stratification of M. supracoracoideus. This muscle may have two distinct layers with separate insertions, as in Pelecanoides; this is also true of Crax rubra (Berger, 1955), penguins (George \& Berger, 1966:313) (although not reported by Schreiweis, 1982), numerous galliforms (Hudson \& Lanzillotti, 1964) and cathartids. The muscle has three parts in Fregata, Sula and Phoenicopterus and four parts in Diomedea (George \& Berger, 1966:313). It is single-layered in Gavia, in grebes (Sanders, 1967), tinamous (Hudson et al., 1972), Polihierax semitorqualus (Berger, 1956a), cuckoos (Berger, 1953, 1954) and hummingbirds (Zusi \& Bentz, 1984); George \& Berger (1966:313) note that most birds have one part only. In Grus the muscle has two parts but the two tendons fuse and there is only one insertion point (Fisher \& Goodman, 1955; Berger, 1956b).

7. Reduction of $\mathrm{M}$. deltoideus major. This muscle is greatly reduced in Pelecanoides. It is small in penguins (Schreiweis, 1982) (Beddard, 1898:86 
reported it as absent in penguins), reduced in swifts and reduced or absent in hummingbirds (Lowe, 1939; Zusi \& Bentz, 1984) and Psittacula (Beddard, 1898:86). It is "poorly developed" in Crax rubra (Berger, 1955), and "normal" in loons, grebes (Sanders, 1967) and most other birds (Fisher, 1946; Berger, 1953, 1954, 1956a, 1956b; Fisher \& Goodman, 1955; Hudson \& Lanzillotti, 1964; George \& Berger, 1966:324-325; Owre, 1967; Hudson el al., 1972). The muscle is well developed in Lari, much smaller in Alcae (Hudson et al., 1969).

8. Reduction of $\mathrm{M}$. biceps brachii. The muscle is well developed in galliforms (Hudson \& Lanzillotti, 1964), tinamous (Hudson et al., 1972), Polihierax (Berger, 1956a), cathartids (Fisher, 1946), Grus (Fisher \& Goodman, 1955; Berger, 1956b), Columba (George \& Berger, 1966) and cuckoos (Berger, 1953, 1954). It is moderately well developed in Gavia, and in grebes (Sanders, 1967), Anhinga and Phalacrocorax (Owre, 1967), Lari and Alcae (Hudson et al., 1969) and hummingbirds (Zusi \& Bentz, 1984), and weakly developed in Pterodroma (Kuroda, 1960) and Pelecanoides. It is vestigial or absent in penguins (Schreiweis, 1982).

9. Presence of the biceps slip of $\mathrm{M}$. biceps brachii. This slip is present in loons; grebes (Sanders, 1967); Grus (Fisher \& Goodman, 1955; Berger, 1956b); cathartids (Fisher, 1946); Lari and Alcae (Hudson et al., 1969); Procellariiformes, Phaethon, Phalacrocorax, Anhinga, Phoenicopterus, Anatidae, Rallidae, Jacanidae, Charadriidae, Columbidae, Caprimulgidae and Coliidae (George \& Berger, 1966:331), galliforms except cracids, numidids and meleagridids (Hudson \& Lanzillotti, 1964). It is absent in Pelecanoides, tinamous (Hudson el al., 1972), and cuckoos (Berger, 1953, 1954). No biceps slip was mentioned for Polihierax (Berger, 1956a). The entire M. biceps brachii is absent in penguins (Schreiweis, 1982).

10. Reduction of M. pronator superficialis. In Pelecanoides this muscle is considerably smaller than M. pronator profundus. It is somewhat reduced in Lari and Alcae (Hudson et al., 1969). This is not the case in Gavia, grebes (Sanders, 1967), tinamous (Hudson et al., 1972), Anhinga and Phalacrocorax (Owre, 1967), Camptorhynchus (Zusi \& Bentz, 1978), cathartids (Fisher, 1946), galliforms (Hudson \& Lanzillotti, 1964), Grus (Fisher \& Goodman, 1955; Berger, 1956b), Polihierax (Berger, 1956a), cuckoos (Berger, 1953, 1954), hummingbirds (Zusi \& Bentz, 1984), nor the species discussed by George \& Berger (1966:345-346). The two pronators are absent in penguins (Schreiweis, 1982).

11. Reduction or absence of M. supinator. This muscle is absent or reduced to an aponeurosis in Pelecanoides; it is weakly developed in Chordeiles and Upupa (George \& Berger, 1966:365) and in penguins (Schreiweis, 1982); apparently fairly small in cathartids (Fisher, 1946) and Grus (Fisher \& Goodman, 1955; Berger, 1956b), of moderate size in Anhinga and Phalacrocorax (Owre, 1967), but present and "normal" in loons, grebes (Sanders, 1967), galliforms (Hudson \& Lanziilotti, 1964), tinamous (Hudson et al., 1972), Camplorhynchus (Zusi \& Bentz, 1978), Lari and Alcae (Hudson et al., 1969), cuckoos (Berger, 1953, 1954), hummingbirds (Zusi \& Bentz, 1984), and all other birds compared by George \& Berger (1966:364-365).

12. M. extensor longus digiti majoris, presence of distal head. This is present in Gavia (although Sanders, 1967 did not find it in Gavia), one specimen of Pelecanoides, most grebes (Sanders, 1967); Anhinga and Phalacrocorax (Owre, 1967), Camptorhynchus (Zusi \& Bentz, 1978); cathartids (flexor metacarpi brevis; 
TABLE 1 Distribution of character states in ingroup and outgroups. $x$, Present; 0 , absent; ?, uncertain; -, presumably unknown. See text for further explanation

\begin{tabular}{|c|c|c|c|c|c|c|c|c|c|c|c|c|c|}
\hline & 1 & 2 & 3 & 4 & 5 & 6 & 7 & 8 & 9 & 10 & 11 & 12 & 13 \\
\hline Gavia & $x$ & 0 & $x$ & $x$ & $x$ & 0 & 0 & 0 & $x$ & 0 & 0 & $\times 0$ & 0 \\
\hline Pterodroma & - & - & - & - & - & - & - & $x$ & - & - & - & $\times 0$ & - \\
\hline Pelecanoides & $x$ & 0 & $x$ & $x$ & 0 & $x$ & $x$ & $x$ & 0 & $x$ & $x$ & $\times 0$ & $\times 0$ \\
\hline Fulmarus & - & 0 & - & - & - & - & - & - & - & - & - & - & - \\
\hline Procellariiformes & - & - & - & $x$ & - & - & - & - & $x$ & - & - & - & - \\
\hline Rhea & - & - & - & - & - & - & - & - & - & - & - & 0 & - \\
\hline tinamous & $x$ & 0 & $x$ & 0 & $?$ & 0 & 0 & 0 & 0 & 0 & 0 & $\times 0$ & 0 \\
\hline grebes & $x$ & 0 & $x$ & 0 & $x$ & 0 & 0 & 0 & $x$ & 0 & 0 & $\times 0$ & 0 \\
\hline Sphenisciformes & $x$ & $\times 0$ & - & $?$ & 0 & $x$ & $x$ & $x$ & 0 & NA & $x$ & 0 & 0 \\
\hline Steganopodes & - & - & - & $x$ & - & - & - & - & - & - & - & - & - \\
\hline Phalacrocorax & 0 & $x$ & $x$ & 0 & 0 & 0 & 0 & 0 & $x$ & 0 & 0 & 0 & 0 \\
\hline Anhinga & 0 & $x$ & $x$ & $x$ & 0 & 0 & 0 & 0 & $x$ & 0 & 0 & 0 & 0 \\
\hline Phaethon & - & - & - & - & - & - & - & - & $x$ & - & - & - & - \\
\hline Ciconiiformes & - & - & - & $x$ & - & - & - & - & - & - & - & - & - \\
\hline Bugeranus & - & - & - & $x$ & - & - & - & - & - & - & - & - & - \\
\hline Balearica & - & - & - & $x$ & - & - & - & - & - & - & - & - & - \\
\hline Scopus & - & - & - & $x$ & - & - & - & - & - & - & - & - & - \\
\hline Phoenicopterus & - & - & - & - & - & $?$ & - & - & $x$ & - & - & - & - \\
\hline Chen & - & - & - & - & - & - & 0 & - & - & - & - & - & - \\
\hline Camptorhynchus & - & - & - & - & - & - & - & - & - & 0 & 0 & $x$ & - \\
\hline anatids & - & - & - & - & $x$ & - & - & - & $x$ & - & - & - & - \\
\hline Polihierax semitorquatus & $x$ & - & - & 0 & 0 & 0 & 0 & 0 & 0 & 0 & - & $x$ & - \\
\hline Accipitres & - & - & - & $x$ & - & - & 0 & - & - & - & - & - & - \\
\hline cathartids & $x$ & $x$ & $?$ & $x$ & 0 & $x$ & 0 & 0 & $x$ & 0 & $x$ & $x$ & 0 \\
\hline galliforms & $x$ & $\times 0$ & 0 & 0 & $?$ & $x$ & 0 & 0 & $x$ & 0 & 0 & $\times 0$ & $\times 0$ \\
\hline Numididae & - & - & - & - & - & - & - & - & 0 & 0 & 0 & $x$ & $x$ \\
\hline Meleagrididae & - & - & - & - & - & - & - & - & 0 & 0 & 0 & $x$ & $x$ \\
\hline Crax rubra & - & - & - & - & - & $x$ & $x$ & - & 0 & 0 & - & 0 & - \\
\hline Rhynochetus & $x$ & - & - & - & - & - & - & - & - & - & - & - & - \\
\hline Grus canadensis & $x$ & 0 & 0 & 0 & 0 & $x$ & 0 & 0 & $x$ & 0 & $x$ & 0 & $x$ \\
\hline G. americana & $x$ & 0 & 0 & $x$ & 0 & $x$ & 0 & 0 & $x$ & 0 & $x$ & 0 & $x$ \\
\hline Rallidae & - & - & - & - & - & - & - & - & $x$ & - & - & - & - \\
\hline Jacanidae & - & - & - & - & - & - & - & - & $x$ & - & - & - & - \\
\hline Charadriidae & - & - & - & - & - & - & - & - & $x$ & - & - & - & - \\
\hline Lari & $x$ & $x$ & $x$ & $x$ & 0 & 0 & 0 & 0 & $x$ & $x$ & 0 & $x$ & $\times 0$ \\
\hline Alcae & $x$ & $x$ & $x$ & $\hat{x}$ & 0 & 0 & $x$ & 0 & $x$ & $x$ & 0 & $x$ & $\times 0$ \\
\hline Columba & - & $?$ & $?$ & - & - & - & - & - & $x$ & 0 & 0 & $x$ & 0 \\
\hline Psittacula & - & - & - & - & - & - & $x$ & - & - & - & - & - & - \\
\hline cuckoos & 0 & 0 & 0 & 0 & 0 & 0 & 0 & 0 & 0 & 0 & 0 & $\times 0$ & 0 \\
\hline tauracos & - & - & - & - & - & - & - & - & - & - & - & 0 & 0 \\
\hline Otus asio & $x$ & $x$ & $x$ & - & - & - & 0 & - & - & - & - & $x$ & $x$ \\
\hline Chordeiles minor & $x$ & - & $x$ & - & - & - & 0 & - & - & - & $x$ & $x$ & - \\
\hline Podargus & - & - & - & - & - & - & - & - & - & - & - & $x$ & - \\
\hline Caprimulgidae & - & - & - & - & - & - & - & - & $x$ & - & - & - & - \\
\hline hummingbirds & 0 & 0 & 0 & $x$ & 0 & 0 & $x$ & 0 & 0 & 0 & 0 & 0 & 0 \\
\hline swifts & - & - & - & - & - & - & $x$ & - & - & - & - & - & - \\
\hline Colius & - & - & - & - & - & - & - & - & $x$ & - & - & $x$ & - \\
\hline Coracias & - & - & - & - & - & - & 0 & - & - & - & - & $x$ & $x$ \\
\hline Pharomachrus mocino & $x$ & - & $x$ & - & - & - & 0 & - & - & - & - & $x$ & $x$ \\
\hline Chloraceryle americana & $x$ & $x$ & - & - & - & - & 0 & - & - & - & - & 0 & $x$ \\
\hline Upupa & - & - & - & - & - & - & - & - & - & - & $x$ & 0 & - \\
\hline Aceros & - & - & - & - & - & - & 0 & - & - & - & - & 0 & $x$ \\
\hline Indicator & - & - & - & - & - & - & - & - & - & - & - & 0 & $x$ \\
\hline Procnias nudicollis & - & $x$ & - & - & - & - & 0 & - & - & - & - & 0 & $x$ \\
\hline tyrannids & 0 & $x$ & 0 & 0 & 0 & 0 & 0 & 0 & 0 & 0 & 0 & 0 & $x$ \\
\hline passerines & 0 & $x$ & 0 & 0 & 0 & 0 & 0 & 0 & 0 & 0 & 0 & 0 & $x$ \\
\hline
\end{tabular}




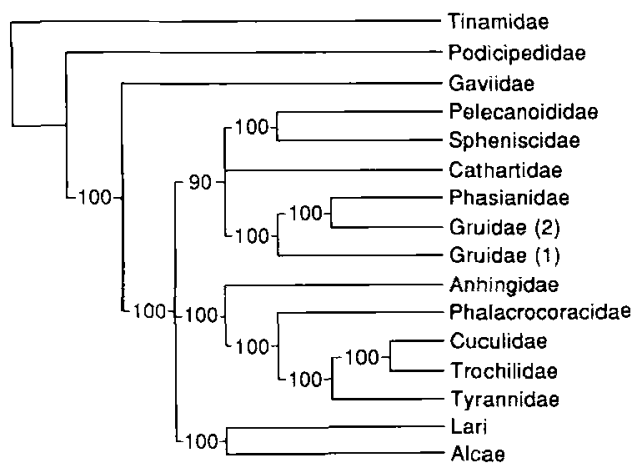

Figure 22. $75 \%$ majority rule consensus tree from numerical cladistic analyses (sec text for explanation).

Fisher, 1946); most galliforms (Hudson \& Lanzillotti, 1964); most tinamous (Hudson et al., 1972); Lari and Alcae (Hudson et al., 1969); Rhea, Chen, Polihierax, Columba, Goura, Otus asio, Podargus, Caprimulgus, Chordeiles, Colius and Coracias (George \& Berger, 1966:367-368). The muscle was reported absent in penguins (Schreisweis, 1982), Crax rubra (Berger, 1955); Grus (Fisher \& Goodman, 1955; Berger, 1956b), some cuckoos (Berger, 1954), hummingbirds (Zusi \& Bentz, 1984), and various other species (George \& Berger, 1966:368).

13. Reduction or absence of $\mathbf{M}$. ulnometacarpalis dorsalis. This is absent in one specimen of Pelecanoides garnati and present in one; it is small in most passerines (McKitrick, 1985b) and in Grus (Berger, 1956b) and Chen, Aceros, Otus, Pharomachrus, Coracias, Chloroceryle and Indicator (George \& Berger, 1966); it is variable in Lari and Alcae (Hudson et al., 1969). It is present in most other birds (Fisher, 1946; Hudson \& Lanzillotti, 1964; George \& Berger, 1966:371; Owre, 1967). It is well developed in penguins (Schreiweis, 1982) and in tinamous (Hudson el al., 1972). George \& Berger (1966) reported it absent in Eugenes fulgens but Zusi \& Bentz (1984) found it in all the hummingbirds they examined.

\section{Phylogenetic analysis}

Ten equally parsimonious trees were found (length $=28$ steps; consistency index $=0.464)$. The data are summarized by a $75 \%$ majority rule consensus tree (Fig. 22).

\section{DISCUSSION}

Several muscles or pairs of muscles of uncertain homology were found in the loons and diving-petrels. (1) Two small muscles arising adjacent to M. serratus profundus occurred in both specimens of Pelecanoides. (2) An apparent M. deltoideus major occurred in both specimens of Pelecanoides, which is the smallest of this muscle ever reported for a bird. (3) Two small muscles arising near the head of $\mathbf{M}$. biceps brachii occurred in one specimen of Gavia immer; the more medial of these was present in the other specimen of $G$. immer but none was 
present in $G$. stellata; the two muscles were represented (apparently) only as ligaments in both specimens of Pelecanoides. Because of the relative scarcity of comparative data on the forelimb myology of birds, little can be said about the identity of these muscles. In future studies of avian forelimb myology, special care should be taken to search for these muscles.

In the phylogenetic analysis, loons (Gaviidae) did not cluster with tubenoses (Pelecanoididae) or with penguins (Spheniscidae), although tubenoses always clustered with penguins. The latter cluster could be due to phylogenetic relationship, or to convergent reduction in some of the same muscles related to the habit of underwater 'flight' in both taxa (but see Raikow, Bicanovsky \& Bledsoe, 1988). The characters uniting these groups are 7-10: reduction of M. deltoideus major $(\mathrm{ci}=0.333$ ), reduction of $\mathrm{M}$. biceps brachii ( $\mathrm{ci}=1.000$ ), biceps slip (absence) $(\mathrm{ci}=0.500)$ and reduction of $\mathrm{M}$. pronator superficialis $(\mathrm{ci}=0.500)$, respectively. Penguins show additional reductions in wing musculature that diving-petrels do not.

The tree topology does not conform to any published phylogenetic hypotheses for these groups, with the exception of the Lari-Alcae clade. This tree should not be regarded as a hypothesis of relationships among the included groups, but simply as an indication that the characters analysed from the forelimb musculature do not presently support monophyly of the groups under investigation.

The results of the present study serve three functions. One is to demonstrate the need for further data on the forelimb musculature of birds in general and the groups under discussion in particular (Table 2), as well as for data from other character systems, morphological or otherwise. The second is to provide a preliminary test of a published hypothesis (Sibley et al., 1988) of the relationship

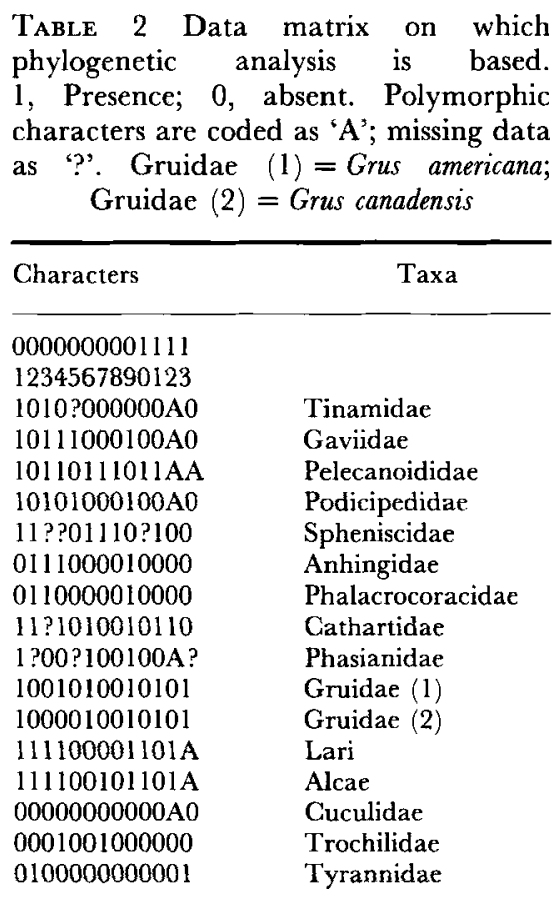


between loons and tubenoses, and as such it does not corroborate that hypothesis. McKitrick (1985a) noted that pitting molecular against morphological data is unproductive if one has already decided that one type of data will consistently yield the correct phylogeny. Many authors have urged the use of all possible evidence to generate phylogenetic hypotheses, most recently Kluge (1989). Kluge (1989) further suggested that characters intrinsic to the organism cannot be said to be independent in the sense of being the products of different biological processes, and adequate scrutiny of hypotheses generated from intrinsic characters may require extrinsic data such as from parasite phylogeny or earth history. Failing this, examining character congruence calls for the use of all possible applicable data as a means of generating 'self-testing' hypotheses, and this may be the best one can achieve in the absence of extrinsic evidence. This means, of course, that the division of characters into "systems" for phylogenetic analysis, such as osteology, myology, behaviour, etc., is arbitrary and for convenience only. In striving to gain access to total evidence, however, we will continue to make these divisions, and the present paper is a part of this unending process.

\section{ACKNOWLEDGEMENTS}

I thank R. J. Raikow, Phil Myers and B. M. OConnor for encouraging me to pursue this study. W. L. Fink and A. G. Kluge provided assistance with the computer analyses and much useful discussion. R. J. Raikow and two anonymous reviewers read an earlier draft of the manuscript and made many improving suggestions. The following generously lent specimens for dissection: K. C. Parkes, D. S. Wood and J. M. Loughlin (Carnegie Museum of Natural History), E. Stickney (Peabody Museum of Natural History, Yale) and R. L. Zusi (National Museum of Natural History, Washington, D.C.). M. Van Bolt rendered my original drawings publishable with a Macintosh computer and ink.

\section{REFERENCES}

BAUMEL, J. J., KING, A. S., LUCAS, A. M. BREAZILE, J. E. \& EVANS, H. E. (Eds), 1979. Nomina anatomica avium. London: Academic Press.

BEDDARD, F. E., 1898. The Structure and Classification of Birds. New York: Longmans, Green and Co.

BERGER, A. J., 1953. On the locomotor anatomy of the blue coua, Coua caerulea. Auk, 70: 49-83.

BERGER, A. J., 1954. The myology of the pectoral appendage of three genera of American cuckoos. Miscellaneous Publications of the Museum of Zoology, University of Michigan, No. 85.

BERGER, A. J, 1955. Notes on the myology of the Great Curassow. Wilson Bulletin, 67: 136-138.

BERGER, A. J., 1956a. The appendicular myology of the pygmy falcon (Politierax semitorquatus). American Midland Naturalist, 55: 326-333.

BERGER, A. J., 1956b. The appendicular myology of the sandhill crane, with comparative remarks on the whooping crane. Wilson Bulletin, 68: 282-304.

BOCK, W. J. \& SHEAR, C. R., 1972. A staining method for gross dissection of vertebrate muscle. Anatomischer Anzeiger, 130: 222-227.

CRACRAFT, J., 1981. Toward a phylogenetic classification of the Recent birds of the world (Class Aves). Auk, 98: $681-714$.

CRACRAFT, J., 1982. Phylogenetic relationships and monophyly of loons, grebes, and hesperornithiform birds, with comments on the early history of birds. Systematic Zoology, 31: 35-56.

CRACRAFT, J., 1988. The major clades of birds. In M. J. Benton (Ed.), The Phylogeny and Classification of the Tetrapods, Vol. I: Amphibians, Reptiles, Birds. Systematics Association Special Volume No. 35A: 339-361. Oxford: Clarendon Press. 
CRACRAFT, J. \& MINDELL, D. P., 1989. The early history of modern birds: A comparison of molecular and morphological evidence. In B. Fernholm, K. Bremer \& H. Jörnvall (Eds), The Hierarchy of Life: 389403. Elsevier Science Publishers B.V.

FISHER, H. I., 1946. Adaptations and comparative anatomy of the locomotor apparatus of New World vultures. American Midland Naturalist, 35: 545-727.

FISHER, H. I. \& GOODMAN, D. C., 1955. The myology of the whooping crane, Grus americana. Illinois Biological Monographs, 24(2). 127 pp.

GADOW, H. \& SELENKA, E., 189l. Vögel. Part I. Anatomischer Theil. In H. G. Bronn (Ed.), Klassen und Ordnungen des Thier-Reichs. Sechster Band, Vierte Abtheilung. Leipzig: C. F. Winter.

GEORGE, J. C. \& BERGER, A. J., 1966. Avian Myology. New York: Academic Press.

HUDSON, G. E. \& LANZILLOTTI, P. J., 1964. Muscles of the pectoral limb in galliform birds. American Midland Naturalist, 71: 1-113.

HUDSON, G. E., SCHREIWEIS, D. O. \& WANG, S. Y. C., 1972. A numerical study of the wing and leg muscles of tinamous (Tinamidae). Northwest Science, 46: 207-255.

HUDSON, G. E., HOFF, K. M., VANDEN BERGE, J. \& TRIVETTE, E. G., 1969. A numerical study of the wing and leg muscles of Lari and Alcae. lbis, 111: $459-524$.

KLUGE, A. G., 1989. A concern for evidence and a phylogenetic hypothesis of relationships among Epicrates (Boidae, Serpentes). Systematic Zoology, 38: 7-25.

KURODA, N., 1960. On the muscular system of the gadfly petrel (Tubinares). Zoological Magazine, 69: 85-89.

KURODA, N., 1961. A note on the pectoral muscles of birds. Auk, 78: 261-263.

LOWE, P. R., 1939. On the systematic position of swifts (Suborder Cypseli) and humming-birds (Suborder Trochili), with special reference to their relation to the Order Passeriformes. Transactions of the Zoological Sociely of London, 24: 307-348.

MAYR, E. \& COTTRELL, G. W. (Eds), 1979. Check-list of Birds of the World, 1, 2nd edn. Cambridge, Massachusetts: Museum of Comparative Zoology.

MCKITRICK, M. C., 1985a. Monophyly of the Tyrannidae (Aves): Comparison of morphology and DNA Systematic Zoology, 34: 35-45.

McKITRICK, M. C., 1985b. Myology of the pectoral appendage in kingbirds (Tyrannus) and their allies. Condor, 87: 402-417.

McKITRICK, M. C., in press. Phylogenetic analysis of avian hind limb musculature. Miscellaneous Publications of the Museum of Zoology, University of Michigan, No. 179.

OWRE, O. T., 1967. Adaptations for locomotion and feeding in the Anhinga and the Double-crested Cormorant. Ornithological Monographs No. 6 .

RAIKOW, R. J., 1977. Pectoral appendage myology of the Hawaiian honeycreepers (Drepanididae). Auk, 94 : $331-342$.

RAIKOW, R. J., 1978. Appendicular myology and relationships of the New World nine-primaried oscines (Aves: Passeriformes). Bulletin of the Carnegie Museum of Natural History No. 7.

RAIKOW, R. J., 1985. Locomotor system. In A. S. King \& J. McLelland (Eds), Form and Function in Birds, 3: 57-147. London: Academic Press.

RAIKOW, R. J., BICANOVSKY, L. \& BLEDSOE, A. H., 1988. Forelimb joint mobility and the evolution of wing-propelled diving in birds. Auk, 105: 446-451.

SANDERS, S. W. H., 1967. The osteology and myology of the pectoral appendage of grebes. Unpublished Ph.D. dissertation, University of Michigan, Ann Arbor.

SGHREIWEIS, D. O., 1982. A comparative study of the appendicular musculature of penguins (Aves: Sphenisciformes). Smithsonian Contributions to Zoology, No. 341 .

SIBLEY, C. G. \& AHLQUIST, J. E., 1972. A comparative study of the egg white proteins of non-passerine birds. Bulletin 39, Peabody Museum of Natural History, Yale University.

SIBLEY, G. G., AHLQUIST, J. E. \& MONROE, B. L. Jr., 1988. A classification of the living birds of the world based on DNA $\times$ DNA hybridization. $A u k, 105: 409-423$.

SWOFFORD, D., 1989. Phylogenetic Analysis Using Parsimony (PAUP), version 3.0e. Champaign, Illinois: Illinois Natural History Survey.

ZUSI, R. L. \& BENTZ, G. D., 1978. The appendicular myology of the Labrador duck (Camptorhynchus labradorius). Condor, 80: 407-408.

ZUSI, R. L. \& BENTZ, G. D., 1984. Myology of the purple-throated carib (Eulampis jugularis) and other hummingbirds (Aves: Trochilidae). Smithsonian Contributions to Zoology, №. 385. 